\title{
Pervasiveness of Communication Disorders and Fatigue in Stroke Patients: A Systematic Scoping Review
}

Ellyn A. Riley ${ }^{1 *}$, Emily Hart ${ }^{2}$, Jonathan L. Preston ${ }^{1}$, Ying $\mathrm{Wu}^{1}$, Sameer Ashaie ${ }^{3,4}$

${ }^{1}$ Department of Communication Sciences and Disorders, Syracuse University, Syracuse, NY, USA

${ }^{2}$ Syracuse University Libraries, Syracuse University, Syracuse, NY, USA

${ }^{3}$ Shirley Ryan Affective and Emotion Rehabilitation Lab, Shirley Ryan AbilityLab, Chicago, IL, USA

${ }^{4}$ Physical Medicine and Rehabilitation, Feinberg School of Medicine, Northwestern University,

Chicago, IL, USA

Short Title: Communication Disorders in Post-Stroke Fatigue Research

${ }^{*}$ Corresponding Author

Ellyn A. Riley

Department of Communication Sciences and Disorders

Syracuse University

621 Skytop Rd. Suite 1200

Syracuse, NY, 13244, USA

Tel: 315-443-9621

Fax: 315-443-4414

E-mail: earil100@syr.edu 


\begin{abstract}
Background - After a stroke, it is highly likely that an individual will experience substantial fatigue that can significantly affect recovery and function; stroke survivors also have more than a $50 \%$ chance of having at least one communication disorder. Current reviews of post-stroke fatigue have not provided evidence focused on communication disorders or the potential influence they may have on post-stroke fatigue and related recovery.
\end{abstract}

Objectives-The aim of this review was to determine how communication disorders are represented in post-stroke fatigue research and to catalogue methods used to identify communication disorders and measure fatigue.

Methods - A systematic, scoping review was conducted to identify studies measuring post-stroke fatigue. To identify these studies, a comprehensive literature search was conducted using relevant databases and grey literature sources, followed by several stages of review that adhered to PRISMA guidelines. We evaluated these studies using pre-established eligibility criteria and extracted data regarding the inclusion/exclusion of persons with communication disorders and the assessment methods used.

Results - The scoping review analysis was conducted on 161 studies. Of these, 41 (26\%) excluded all communication disorders, 71 (44\%) excluded severe communication disorders, and 49 (30\%) included participants with communication disorders. Of the 120 studies that did not explicitly exclude all communication disorders, only 34 were confirmed to report data from at least one person with a communication disorder. Further, only 5 studies reported data that could be used to determine a relationship between these comorbidities.

Conclusions-Persons with communication disorders are underrepresented in post-stroke fatigue research and very few studies have examined the relationship between post-stroke fatigue and communication disorders, limiting conclusions that can be drawn. This is problematic because medical professionals relying on this evidence to guide clinical practice are likely to be treating individuals with co-occurring fatigue and communication disorders and the current research does not provide enough information about the potential impact of fatigue on communication disorders or vice versa. To bridge this gap, we suggest methods of assessment that could provide ways to more accurately 1 ) reflect the real patient population in post-stroke fatigue studies, and 2) measure and document fatigue in post-stroke communication disorder studies.

Keywords: fatigue, sleepiness, stroke, communication disorders, scoping review 


\section{Introduction}

Recent systematic reviews have found there is a relatively high prevalence and significance of fatigue in the post-stroke population (Choi-Kwon \& Kim, 2011; Cumming, Packer, Kramer, \& English, 2016). The prevalence of post-stroke fatigue ranges from $23-85 \%$ with $40 \%$ reporting fatigue as one of the worst consequences of stroke (Choi-Kwon \& Kim, 2011; Cumming et al., 2016; Staub \& Bogousslavsky, 2001). Excessive daytime sleepiness has also been reported to significantly affect the stroke population (Davies, Rodgers, Walshaw, James, \& Gibson, 2003; Sterr, Herron, Dijk, \& Ellis, 2008). Sleepiness and fatigue represent two distinct concepts, yet these two terms are often used interchangeably in the medical literature (Shen, Barbera, \& Shapiro, 2006). Given their common use and the frequent confusion surrounding these terms, it is often difficult to determine which specific phenomenon a research study aims to measure. In order to be as comprehensive as possible in our scoping review, we decided to include both types of measures and considered the terms interchangeable for this purpose. We will not make a further distinction between the terms 'sleepiness' and 'fatigue' and will use the term 'fatigue' to refer to these related concepts throughout the remainder of the manuscript.

A variety of factors have been found to affect fatigue, including stroke characteristics, co-morbidities, pre-stroke fatigue, and other personal factors (e.g., age, sex, level of support) (Lerdal et al., 2009). We have proposed a revised version of the Lerdal et al. model that considers the role of speech and language disorders (available on the Open Science Framework repository at https://osf.io/48vj5/). Most systematic reviews have focused on chronic neurological fatigue, the prevalence of and factors associated with post-stroke fatigue, or nursing interventions for fatigue (Chaudhuri \& Behan, 2004; Choi-Kwon \& Kim, 2011; Choi-Kwon, Mitchell, \& Kim, 2015; Ponchel, Bombois, Bordet, \& Hénon, 2015). One factor that systematic reviews suggest contributes to post-stroke fatigue is communication disorders. However, these reviews either do not cite direct evidence to support specific claims or cite sources that do not distinguish between communication disorders and cognitive impairment (Radman et al., 2012). Reviews that do include specific evidence cite the same two studies: one reporting a significant relationship between fatigue and presence of dysarthria, a motor speech disorder (Choi-Kwon, Han, Kwon, \& Kim, 2005), and the other reporting the results of a large survey study that identified fatigue and speech impairment solely through patient self-report (Glader, Stegmayr, \& Asplund, 2002). An additional issue arising from these studies is the inconsistent and interchangeable use of the terms referring to communication disorders (e.g., speech disorder, speech impairment, aphasia). 
The term 'communication disorder' encompasses a broad range of speech and language disorders, including aphasia and motor speech disorders. Aphasia is a language disorder that has been estimated to occur in approximately $30 \%$ of those who have experienced an ischemic stroke (Engelter et al., 2006; Flowers, Silver, Fang, Rochon, \& Martino, 2013). Persons with aphasia (PWA) can have difficulty understanding and producing both spoken and written language and variations in aphasia type and severity results in individual patterns of language deficit. Apraxia of speech and dysarthria are motor speech disorders (MSD) that are estimated to occur in approximately $11 \%$ and $42 \%$ of first-time stroke survivors, respectively (Flowers et al., 2013; Lawrence, Booth, Mercer, \& Crawford, 2013). Persons with MSDs experience difficulty with speech production, but do not have impaired comprehension. To further complicate the issue, it is estimated that aphasia and dysarthria co-occur in approximately $15 \%$ of first-time stroke survivors, and those with apraxia of speech have a $50 \%$ chance of also having dysarthria and an even higher chance of having co-occurring aphasia(Flowers et al., 2013). Given these estimates, persons who have experienced a stroke have more than a 50\% chance of having at least one communication impairment (Flowers et al., 2013). Thus, for this scoping review, we will refer to persons with communication disorders (PWCD) to mean an individual with aphasia and/or a motor speech disorder.

Many of the measures used to diagnose post-stroke fatigue are highly dependent on language comprehension and production and are administered as questionnaires (e.g., Fatigue Severity Scale; Epworth Sleepiness Scale) (Shen et al., 2006). These measures present a significant challenge to diagnosing post-stroke fatigue in PWCD because they rely on intact language comprehension. Some reviews have noted that communication disorders like aphasia and MSDs often disqualify individuals from participating in studies that use common fatigue measures (Choi-Kwon \& Kim, 2011; Cumming et al., 2016). Furthermore, challenges of evaluating PWCD also contributes to our poor understanding of the relationship between communication disorders and post-stroke fatigue (Ponchel et al., 2015). Although this observation has been occasionally noted in post-stroke fatigue studies, thus far, there have been no systematic investigations of the actual representation of PWCD in this body of literature.

The incidence and prevalence of fatigue in the post-stroke population is relatively high and statistically, many of these individuals are likely to also have communication disorders. If PWCD are frequently excluded from post-stroke fatigue studies, it is possible that underrepresentation of communication disorders in this research could result in an underestimation of the prevalence of post-stroke fatigue and in misleading conclusions about the factors that may contribute to fatigue (Choi-Kwon \& Kim, 2011; Cumming et al., 2016). Without a systematic investigation of this claim, one cannot accurately conclude that persons with communication disorders are underrepresented in this 
research. Furthermore, it also remains unknown if traditional language-based fatigue measures can be used with individuals who have communication disorders.

For post-stroke fatigue studies that have considered whether or not to include PWCD, a cursory look at the literature suggests that methods of identifying communication disorders are quite variable and descriptions of these methods also vary greatly in the level of detail provided. In order to fully understand the role of fatigue and communication disorders in stroke patients, it is essential to first understand how communication disorders have typically been identified in this type of research so that recommendations can be offered as to which methods are most appropriate.

Others have suggested that few studies have addressed the relationship between language ability and fatigue (Ponchel et al., 2015) and it remains unclear if findings across these studies support the claim that having a communication disorder increases the chances or severity of fatigue. Given the currently available literature reviews focusing on post-stroke fatigue, this question is still difficult to answer because it is unclear how many of the studies contained in these reviews actually included persons with communication disorders.

The purpose of this study was to 1) determine the extent to which existing literature on fatigue in stroke patients includes PWCD, and 2) to catalogue the methods used in these studies to identify communication disorders (i.e., aphasia and MSD). We hypothesized that relatively few post-stroke fatigue studies would address communication disorders and that a wide variety of methods would be used to identify them.

\section{Methods}

To address study aims, a systematic scoping review was conducted. The review protocol is registered in Prospero, the International prospective registry of systematic reviews, Registration Number: CRD42018088053, URL: https://www.crd.york.ac.uk/prospero/display record.php?RecordID=88053, and adheres to PRISMA guidelines.

\subsection{Search protocol and study identification}

A comprehensive search of the literature was conducted to identify studies measuring patient fatigue, either quantitatively or qualitatively, in any phase of stroke recovery. The databases searched included: PubMed, MEDLINE (Web of Science), The Cochrane Library, Scopus, Web of Science, PsycINFO, CINAHL, Google Scholar, Linguistics and Language Behavior Abstracts, Communication Source, Speech Pathology Database for Best Interventions and Treatment Efficacy (speechBITE), Communication Science and Disorders Information Service (ComDisDome), BioMed Central, Embase, and ClinicalTrials.gov. A search for pre-prints and grey literature was also performed 
to look for clinical trials with published results and conference proceedings. Reference lists and cited references from sentinel articles were reviewed to locate additional studies, and we used the related citations function in PubMed. There were no publication date filters applied to the search, and results contained articles up through April of 2020. Keywords used in the search, and the search strategy for PubMed, are included in Appendix A. The Yale MeSH Analyzer (Cushing/Whitney Medical Library, 2015) was used to help identify relevant MeSH terms (Grossetta Nardini \& Wang, 2018).

\subsection{Study selection criteria}

To guide our study selection and eligibility criteria, we used the SPIDER framework ( $\underline{\text { Sample, }}$ Phenomenon of Interest, ㅌesign, Evaluation, Research type). PICO is the most popular framework for systematically reviewing interventions and is most appropriate for evaluating questions of effectiveness; however, alternative frameworks (e.g., SPIDER), are more commonly used in reviews where mixed methods or qualitative studies are included (Littlewood \& Kloukos, 2019). Given that our systematic scoping review would include qualitative, quantitative, and mixed methods studies, we selected the SPIDER framework (Cooke, Smith, \& Booth, 2012; Littlewood \& Kloukos, 2019). Table 1 shows our application of the SPIDER tool to frame our primary research question: How frequently do patient groups in post-stroke fatigue studies include patients with communication disorders? Table 2 lists our eligibility criteria as they relate to the individual components of our research question. Studies were excluded if they did not meet one of the listed criteria, were not in English, or did not report original data (e.g. reviews, comments, letters).

\subsection{Study selection and critical appraisal}

We used the CADIMA Evidence Synthesis Tool (https://www.cadima.info/index.php/area/evidenceSynthesisDatabase) to manage the following processes during the scoping review: combining search results, the deduplication of studies in combination with the citation management program Zotero, the title/abstract and full text reviews, data extraction, and critical appraisal. Reviewers $A$ and $B$ each assessed half of the 2,333 results identified in the literature search for their relevance (focus on fatigue) and inclusion of the population of interest (stroke participants). If title/abstract content was not comprehensive enough to clearly exclude the article at this stage, it proceeded to full-text review. Any questions about title/abstract eligibility were resolved by Reviewer $A$. The full text of 1,125 studies were then assessed for eligibility using criteria in Table 2. Reviewers A, C, D, and E each reviewed $25 \%$ of these studies and reliability was completed on $30 \%$ of the studies for each reviewer (e.g., Reviewer $A$ completed independent reliability scoring for $30 \%$ of the studies reviewed by Reviewer $\mathrm{C}$ ). See Figure 1, PRISMA Flow Diagram for the study selection process and details regarding the 723 articles 
excluded during the full-text review stage. A total of 402 articles reached the critical appraisal stage. Each article was assessed by Reviewer A for methodological quality using the inclusion/exclusion criteria outlined in Table 3. Reviewers C, D, and E each completed a reliability check on a third of the articles in the critical appraisal stage. Based on the critical appraisal criteria, 241 additional studies were excluded at this stage.

\subsection{Data collection and analysis}

Reviewers C, D, and E each completed data extraction for a third of the articles remaining after critical appraisal (see Appendix B for data extracted for each study; see Tables 4 and 5 for lists of tests). Reviewer A completed independent reliability on $10 \%$ of the articles for each reviewer to ensure accuracy and consistency. The following data were extracted from each eligible study to use for subsequent analysis: general study purpose (descriptive/observational, intervention); sample source (e.g., hospital, skilled nursing); method used to measure fatigue (e.g., self-report scale, structured interview); name of fatigue measure; purpose of fatigue measure (e.g., to qualify participants, study outcome); method used to identify communication disorder (e.g., specific test, previous diagnosis); name of communication disorder measure; inclusion/exclusion status of PWCD (e.g., exclude all communication disorders); verification status of inclusion of PWCD.

Primary data analysis and results synthesis were carried out on the remaining 161 studies by Reviewer A, using Excel software. Frequency data for were summarized to determine the percentage of post-stroke fatigue studies that 1) excluded all PWCD, 2) excluded only severe PWCD, and 3) included PWCD. The number of studies using each specific fatigue measure and each specific measure to identify communication disorders were also summarized with percentages. Detailed data are provided in Appendix B and in Tables 4 and 5.

As a secondary analysis, Reviewer A examined the 161 studies to determine how many of these reported data from at least one PWCD. To meet this criterion, a study needed to include at least one verified PWCD and have either reported raw data from the fatigue measure specifically for this population or have reported a direct comparison between PWCD and another group without communication disorders. Results of this categorization process for each article are included in the Appendix B.

\subsection{Risk of bias}

In an attempt to mitigate bias, 4 reviewers and 1 librarian participated in this systematic scoping review. Reviewers independently evaluated studies and performed reliability checks across all stages of selection and evaluation. Given that the aim of this study was to provide a broad, scoping 
overview of the representation of communication disorders in the existing body of post-stroke fatigue literature, we focused on reporting population data related to our study questions and only assessed the methodological quality of the inclusion/exclusion criteria for those studies.

\section{Results}

A total of 2,333 records were identified through our literature searches (after duplicates were removed) and screened using their titles and abstracts. We assessed the full text of 1,125 articles and further excluded 723 articles, resulting in 402 articles included in the critical appraisal stage. From this process, another 241 articles were excluded, leaving 161 articles that were included in our final analysis (see Figure 1). Inter-rater reliability across reviewers was high, with an average of $95 \%$ overlap in the full-text review stage and $98 \%$ overlap in the critical appraisal stage.

Of the 161 studies included in our final review, 49 (30\%) explicitly allowed communication disorders, 41 (26\%) excluded all communication disorders, and 71 (44\%) specifically excluded severe communication disorders (Figure 2a).

Of the 120 post-stroke fatigue studies that did not explicitly exclude all PWCD, a total of 34 (28\%) were confirmed to measure fatigue in at least one participant with a communication disorder. If we consider the actual total number of post-stroke fatigue studies identified (prior to the critical appraisal stage which eliminated studies that did not thoroughly describe inclusionary/exclusionary criteria), only $8.5 \%$ of studies investigating post-stroke fatigue reported data from at least one participant with a communication disorder. Furthermore, only 5 of these studies included at least one participant with a communication disorder and directly addressed the relationship between communication disorders and fatigue.

Of the 161 studies included in our analysis, a total of $16(10 \%)$ identified communication disorders by experimenter/clinician observation, $3(2 \%)$ used patient self-report, $40(25 \%)$ used a previous diagnosis, 10 (6\%) administered a general stroke screening, 17 (10\%) administered a specific aphasia and/or language test, and 75 (47\%) did not provide enough information to determine how communication disorders were identified in their study sample (Figure 2b). Of the 10 studies that used a general stroke screening to identify persons with communication disorders, the NIH Stroke Scale was the most commonly used screening. Of the 17 studies that used specific aphasia and/or language tests to identify persons with communication disorders, the Token Test was most commonly used. Other screenings and language tests were rarely used (see Table 4).

Although some studies measured fatigue for multiple purposes, the most common purpose of fatigue measurement was to measure once as a study outcome $(117,71 \%)$ and several measured fatigue to 
study change over time $(42,26 \%)$. Very few fatigue measures were used to qualify participants for a study $(4,2 \%)$, or were administered to determine termination time of an experiment $(1,1 \%)$ (Figure 2c). The most common method of measuring fatigue was by using a patient self-report scale (128, $80 \%)$. Fewer studies used structured interviews $(17,10 \%)$ observer-rated scales $(4,3 \%)$, or multiple fatigue/sleepiness measurement methods (12, 7\%) (Figure 2d). Two specific assessments, the Fatigue Severity Scale (FSS) and the Epworth Sleepiness Scale (ESS), were the most commonly used methods of measuring fatigue. While other types of tests were used in these studies, they were rare (Table 5).

\section{Discussion}

This systematic, scoping review of 161 studies, shows that information about communication disorder status in post-stroke sleepiness and fatigue research is limited. The chance that a person who has experienced a stroke will also have a communication disorder is over $50 \%$, yet our results showed that only $8.5 \%$ of all post-stroke fatigue studies ( 34 out of 402 selected before critical appraisal stage), were confirmed to have included at least one participant with a communication disorder (Flowers et al., 2013). Furthermore, even if communication disorders were reported within a study, the percentage of PWCD for most studies was still extremely low and not at all close to what we would expect to see in the real-world stroke population. These findings suggest that persons with communication disorders are severely underrepresented in post-stroke fatigue research, and confirms the informal observations others have reported regarding the frequent exclusion of this population (Choi-Kwon \& Kim, 2011; Cumming et al., 2016).

Most (47\%) of the 161 studies that claimed to include or exclude communication disorders did not provide information about how these disorders were identified. Of those that provided information, about $16 \%$ of the 161 studies administered a test or screening, while the majority of study authors relied primarily on participants' previous diagnoses.

The most common stroke screening used to identify communication disorders was the NIH Stroke Scale (NIHSS). This measure is designed to measure stroke severity and contains two subsections that are relevant to identifying communication disorders. The 'best language' subsection uses a 0-3 observer-rated scale to determine whether an individual has no aphasia (score $=0$ ), mild-tomoderate aphasia (score $=1$ ), severe aphasia (score $=2$ ), or mute/global aphasia (score $=3$ ). The 'dysarthria' subsection uses a 0-2 observer-rated scale to determine whether an individual has no dysarthria $($ score $=0$ ), mild-to-moderate dysarthria $($ score $=1)$, or severe dysarthria (score $=2$ ). The NIHSS has a relatively high intra- and inter-rater reliability across medical and non-medical staff and can be used to measure clinically-significant change (Kwah \& Diong, 2014).

The most common specific language test used to identify communication disorders was the Token Test (De Renzi \& Vignolo, 1962). The Token Test is designed to measure receptive language ability 
(i.e., spoken language comprehension), but does not provide information about speech or language production. This test is not designed to determine disorder severity and therefore may not be the most useful test for identifying individuals with communication disorders. The Frenchay Aphasia Screening Test (FAST), however, was designed to be used by individuals who are not specially trained to identify communication disorders, can be administered quickly ( $<10$ minutes), and provides a cutoff score for presence/absence of aphasia (Enderby, Wood, Wade, \& Hewer, 1986). The FAST was also concluded to be the most comprehensively evaluated aphasia screening test available and is highly sensitive to identifying individuals with communication disorders (O'Neill, Cheadle, Wyatt, McGuffog, \& Fullerton, 1990; Salter, Jutai, Foley, Hellings, \& Teasell, 2006). These characteristics make the FAST an ideal tool for identifying communication disorders in the stroke population, therefore we suggest that future studies of post-stroke fatigue should consider using it. The FAST may be particularly useful when the researchers or clinicians have no background knowledge or training to specifically diagnose speech and language disorders.

For the studies that may have included individuals with communication disorders, the majority (130, $80 \%)$ used patient self-report scales of fatigue. The most commonly reported fatigue measure was the Fatigue Severity Scale (FSS), followed by the Epworth Sleepiness Scale (ESS), the Multidimensional Fatigue Inventory (MFI), and the Fatigue Assessment Scale (FAS) (Johns, 1991; Krupp, LaRocca, Muir-Nash, \& Steinberg, 1989; Michielsen, De Vries, \& Van Heck, 2003; Smets, Garssen, Bonke, \& De Haes, 1995). All four of these measures require an individual to rate written statements about different aspects of fatigue using variations of Likert-type scales (e.g., strongly disagree to strongly agree (Likert, 1932)). Depending on the type and severity of an individual's communication disorder, completing self-report scales such as these may present significant challenges, particularly when additional supports or modifications are not provided to these individuals. For example, Riley, Owora, McCleary, and Anderson (2019) developed and implemented a modified version of the ESS and the Visual Analog Fatigue Scale (VAFS) to measure sleepiness and fatigue in persons with aphasia. These modifications included providing both verbal and written instructions, slowing speech rate, repeating instructions, and using a visually augmented response scale to ensure understanding of each rating. Modifications such as these are relatively simple to implement and can significantly improve patients' abilities to complete these common fatigue measures. For communication disorders researchers and speech-language clinicians who are unfamiliar with measuring fatigue, modified versions of the ESS and VAFS can be a great way to track and record self-reported fatigue in PWCD during research studies or clinical treatment (Riley et al., 2019).

We were also interested in how fatigue measures in these studies were being used to identify and quantify fatigue. In a previous survey study of speech-language pathologists (SLPs), findings indicated 
that intensive rehabilitation could be contributing to fatigue in persons with aphasia, suggesting that it might be beneficial to look for evidence of within-session or task-based fatigue in the post-stroke research (Riley, 2017). In our review, we found that most studies measured presence or degree of fatigue as a primary study outcome or measured fatigue over the course of weeks or months to examine change over time. Very few studies attempted to measure fatigue within the same session or compare fatigue measures administered immediately before and after a task. Of the studies that did measure fatigue change within-session, none were related to speech therapy. Given that SLPS perceive increased fatigue in their patients related to speech and language therapy, additional studies are needed to more specifically measure the relationship between specific tasks and fatigue (Riley, 2017).

\subsection{Study limitations}

Although we attempted to be as comprehensive as possible in our initial searches and screenings of the literature, it is possible that a relevant study was overlooked. For example, in our critical appraisal stage, per our inclusion/exclusion criteria, we eliminated any studies that failed to provide enough detail about whether or not PWCD were included or excluded from the study. This step was intended to decrease reporting bias to ensure that we were not unfairly counting a study as excluding PWCD if participant status could not be determined from the description; however, it is possible that studies excluded in the critical appraisal stage actually did exclude or include PWCD, but did not report it.

\subsection{Conclusions \& clinical recommendations}

The primary finding of this review is that communication disorders are underrepresented in poststroke fatigue research. Most post-stroke fatigue studies did not provide enough information to determine how they identified communication disorders in potential participants, and the fatigue measures most frequently used were heavily dependent on language. Based on these findings, we recommend that future research investigating post-stroke fatigue should include participants with communication disorders, use comprehensive and validated measures to identify these individuals, and modify administration of subjective fatigue measures in order to make them more accessible to this population. Additionally, we recommend that future research investigating post-stroke communication disorders should include appropriately modified fatigue measures to report patients' perceived fatigue as it relates to treatment and recovery.

Although none of the studies included in this scoping review specifically investigated the impact of speech therapy on fatigue, given what has been reported by speech-language pathologists (Riley, 2017), there is probably good reason for clinicians to be aware of fatigue in patients with communication disorders. A related concept, vigilant attention, is associated with performance in 
language therapy, with low levels of attention resulting in more errors in therapy (Riley et al., 2019). Rehabilitation therapy sessions (e.g., speech, physical, occupational) may contribute to fatigue and reduce vigilant attention in person with aphasia, therefore, we suggest that clinicians and researchers take pertinent steps to minimize fatigue in these sessions. For example, some persons with aphasia may benefit from frequent breaks during therapy sessions. Others may benefit from alternating therapy tasks throughout a session to prevent task-specific fatigue. Furthermore, clinicians and researchers should strive to find the time of the day where patients are least fatigued to schedule therapy sessions. Clinicians and researchers should also monitor how general fatigue (e.g., due to travelling) may impact a patient vs. fatigue from the therapy itself. Different types of fatigue may require different solutions. For example, if individuals with aphasia experience fatigue related to a particular task, that task might be scheduled separately or towards the end of a session whereas more general fatigue might be reduced by allowing a rest period before starting a therapy session. Structuring therapy in this way may reduce the impact of fatigue on performance during the therapy session and ultimately aid in improving response to treatment. Results of this scoping review have revealed that although there are hundreds of studies investigating post-stroke fatigue, there are not yet enough data available in the literature to evaluate the potential impact of fatigue on persons with communication disorders. Until this significant gap in knowledge is filled, SLP clinicians will not have the tools and guidance they need to maximally facilitate recovery in patients with post-stroke communication disorders and co-occurring fatigue. 


\section{References}

Chaudhuri, A., \& Behan, P. O. (2004). Fatigue in neurological disorders . Lancet (London, England) , 363(9413), 978-988. https://doi.org/10.1016/S0140-6736(04)15794-2

Choi-Kwon, S., Han, S. W., Kwon, S. U., \& Kim, J. S. (2005). Poststroke Fatigue: Characteristics and Related Factors. Cerebrovascular Diseases, 19(2), 84-90. https://doi.org/10.1159/000082784

Choi-Kwon, S., \& Kim, J. S. (2011). Poststroke Fatigue: An Emerging, Critical Issue in Stroke Medicine. International Journal of Stroke, 6(4), 328-336. https://doi.org/10.1111/j.1747-4949.2011.00624.x

Choi-Kwon, S., Mitchell, P. H., Kim, J. S., \& Choi-Kwon, S. (2015). Nursing Interventions for Poststroke Fatigue. Stroke (00392499), 46(10), e224-e227. https://doi.org/10.1161/STROKEAHA.115.009534

Cooke, A., Smith, D., \& Booth, A. (2012). Beyond PICO: The SPIDER tool for qualitative evidence synthesis. Qualitative Health Research, 22(10), 1435-1443.

Cumming, T. B., Packer, M., Kramer, S. F., \& English, C. (2016). The prevalence of fatigue after stroke: A systematic review and meta-analysis. International Journal of Stroke, 11(9), 968-977. https://doi.org/10.1177/1747493016669861

Cushing/Whitney Medical Library. (2015). Yale MeSH analyzer [Internet]. http://mesh.med.yale.edu/

Davies, D. P., Rodgers, H., Walshaw, D., James, O. F. W., \& Gibson, G. J. (2003). Snoring, daytime sleepiness and stroke: A case-control study of first-ever stroke. Journal of Sleep Research, 12(4), 313-318. https://doi.org/10.1046/j.09621105.2003.00371.x

De Renzi, E., \& Vignolo, L. A. (1962). The Token Test: A Sensitive Test To Detect Receptive Disturbances In Aphasics. Brain, 85(4), 665-678. https://doi.org/10.1093/brain/85.4.665

Enderby, P. M., Wood, V. A., Wade, D. T., \& Hewer, R. L. (1986). The Frenchay Aphasia Screening Test: a short, simple test for aphasia appropriate for non-specialists. International Rehabilitation Medicine, 8(4), 166-170. https://doi.org/10.3109/03790798709166209

Engelter, S. T., Gostynski, M., Papa, S., Frei, M., Born, C., Ajdacic-Gross, V., Gutzwiller, F., \& Lyrer, P. A. (2006). Epidemiology of Aphasia Attributable to First Ischemic Stroke. Stroke, 37(6), 1379-1384.

https://doi.org/10.1161/01.STR.0000221815.64093.8c

Flowers, H. L., Silver, F. L., Fang, J., Rochon, E., \& Martino, R. (2013). The incidence, co-occurrence, and predictors of dysphagia, dysarthria, and aphasia after first-ever acute ischemic stroke. Journal of Communication Disorders, 46(3), 238-248. https://doi.org/10.1016/j.jcomdis.2013.04.001

Glader, E., Stegmayr, B., Asplund, K., Glader, E.-L., Stegmayr, B., \& Asplund, K. (2002). Poststroke fatigue: a 2-year follow-up study of stroke patients in Sweden. Stroke (00392499), 33(5), 1327-1333. https://doi.org/10.1161/01.STR.0000014248.28711.D6

Johns, M. W. (1991). A New Method for Measuring Daytime Sleepiness: The Epworth Sleepiness Scale. Sleep, 14(6), 540545. https://doi.org/10.1093/sleep/14.6.540

Krupp, L. B. (1989). The Fatigue Severity Scale. Archives of Neurology, 46(10), 1121. https://doi.org/10.1001/archneur.1989.00520460115022

Kwah, L. K., \& Diong, J. (2014). National Institutes of Health Stroke Scale (NIHSS). Journal of Physiotherapy, 60(1), 61. https://doi.org/10.1016/j.jphys.2013.12.012 
Lawrence, M., Booth, J., Mercer, S., \& Crawford, E. (2013). A systematic review of the benefits of mindfulness-based interventions following transient ischemic attack and stroke. International Journal of Stroke, 8(6), 465-474. https://doi.org/10.1111/ijs.12135

Lerdal, A., Bakken, L. N., Kouwenhoven, S. E., Pedersen, G., Kirkevold, M., Finset, A., \& Kim, H. S. (2009). Poststroke Fatigue-A Review. Journal of Pain and Symptom Management, 38(6), 928-949. https://doi.org/10.1016/j.jpainsymman.2009.04.028

Likert, R. (1932). A technique for the measurement of attitudes. Archives of Psychology. https://psycnet.apa.org/record/1933-01885-001

Littlewood, A. \& Kloukos, D. (2019). Searching the literature for studies for a systematic review. Part 1: Identifying search concepts in a question. American Journal of Orthodontics and Dentofacial Orthopedics, 155(2), 299-301.

Michielsen, H. J., De Vries, J., \& Van Heck, G. L. (2003). Psychometric qualities of a brief self-rated fatigue measure. Journal of Psychosomatic Research, 54(4), 345-352. https://doi.org/10.1016/S0022-3999(02)00392-6

O'Neill, P., Cheadle, B., Wyatt, R., McGuffog, J., \& Fullerton, K. (1990). The value of the Frenchay Aphasia Screening Test in screening for dysphasia: better than the clinician? Clinical Rehabilitation, 4(2), 123-128. https://doi.org/10.1177/026921559000400205

Ponchel, A., Bombois, S., Bordet, R., \& Hénon, H. (2015). Factors Associated with Poststroke Fatigue: A Systematic Review. In Stroke Research and Treatment (Vol. 2015). Hindawi Publishing Corporation. https://doi.org/10.1155/2015/347920

Radman, N., Staub, F., Aboulafia-Brakha, T., Berney, A., Bogousslavsky, J., \& Annoni, J.-M. (2012). Poststroke fatigue following minor infarcts: A prospective study. Neurology, 79(14), 1422-1427. https://doi.org/10.1212/WNL.0b013e31826d5f3a

Riley, E. A. (2017). Patient Fatigue During Aphasia Treatment: A Survey of Speech-Language Pathologists. Communication Disorders Quarterly, 38(3), 143-153. https://doi.org/10.1177/1525740116656330

Riley, E. A., Owora, A., McCleary, J., \& Anderson, A. (2019). Sleepiness, Exertion Fatigue, Arousal, and Vigilant Attention in Persons With Chronic Aphasia. American Journal of Speech-Language Pathology, 28(4), 1491-1508. https://doi.org/10.1044/2019_AJSLP-18-0301

Salter, K., Jutai, J., Foley, N., Hellings, C., \& Teasell, R. (2006). Identification of aphasia post stroke: A review of screening assessment tools. Brain Injury, 20(6), 559-568. https://doi.org/10.1080/02699050600744087

Shen, J., Barbera, J., \& Shapiro, C. M. (2006). Distinguishing sleepiness and fatigue: focus on definition and measurement. Sleep Medicine Reviews, 10(1), 63-76. https://doi.org/10.1016/j.smrv.2005.05.004

Smets, E. M. A., Garssen, B., Bonke, B., \& De Haes, J. C. J. M. (1995). The multidimensional Fatigue Inventory (MFI) psychometric qualities of an instrument to assess fatigue. Journal of Psychosomatic Research, 39(3), 315-325. https://doi.org/10.1016/0022-3999(94)00125-0

Staub, F., \& Bogousslavsky, J. (2001). Fatigue after stroke: A major but neglected issue. CEREBROVASCULAR DISEASES, 12(2), 75-81. https://doi.org/10.1159/000047685

Sterr, A., Herron, K., Dijk, D.-J., \& Ellis, J. (2008). Time to wake-up: Sleep problems and daytime sleepiness in long-term stroke survivors. Brain Injury, 22(7-8), 575-579. https://doi.org/10.1080/02699050802189727 
Table 1. Application of SPIDER framework for formulating research question.

\begin{tabular}{|l|l|l|}
\hline SPIDER Category & General Definition & Applied to this Scoping Review \\
\hline Sample & Who is the group being studied? & $\begin{array}{l}\text { Post-stroke patients included in } \\
\text { research studies measuring fatigue }\end{array}$ \\
\hline $\begin{array}{l}\text { Phenomenon of } \\
\text { Interest }\end{array}$ & $\begin{array}{l}\text { What are the reasons for examining this } \\
\text { sample? }\end{array}$ & $\begin{array}{l}\text { Communication disorders and } \\
\text { fatigue both highly prevalent in post- } \\
\text { stroke patients }\end{array}$ \\
\hline$\underline{\text { Design }}$ & How have the data been collected? & Interviews, rating scales, observation \\
\hline Evaluation & What is the outcome being impacted? & $\begin{array}{l}\text { Primary: Inclusion and exclusion of } \\
\text { patients with communication } \\
\text { disorders } \\
\text { Secondary: Methods used to identify } \\
\text { communication disorders and } \\
\text { measure fatigue }\end{array}$ \\
\hline$\underline{\text { Research type }}$ & What type of research is included? & $\begin{array}{l}\text { Qualitative, quantitative, mixed } \\
\text { methods. }\end{array}$ \\
\hline
\end{tabular}


Table 2. Selection and eligibility criteria for systematic scoping review

\begin{tabular}{|c|c|c|}
\hline SPIDER Category & Related Eligibility Criteria & How Applied \\
\hline Sample & $\begin{array}{l}\text { Adults with stroke are included as a target population } \\
\text { in the study. }\end{array}$ & If no, study was excluded. \\
\hline \multirow[t]{3}{*}{$\begin{array}{l}\text { Phenomenon of } \\
\text { Interest }\end{array}$} & $\begin{array}{l}\text { Study includes at least one participant with type of } \\
\text { stroke likely to be associated with communication } \\
\text { disorders (e.g., left hemisphere MCA stroke). }\end{array}$ & If no, study was excluded. \\
\hline & $\begin{array}{l}\text { Study provides an operational definition of } \\
\text { fatigue/sleepiness. }\end{array}$ & If no, study was excluded. \\
\hline & $\begin{array}{l}\text { Study defines fatigue/sleepiness in terms related only } \\
\text { to physical activity. }\end{array}$ & If yes, study was excluded. \\
\hline \multirow[t]{2}{*}{ Design } & $\begin{array}{l}\text { Study includes at least } 1 \text { quantitative or qualitative } \\
\text { measure of fatigue/sleepiness. }\end{array}$ & If no, study was excluded. \\
\hline & $\begin{array}{l}\text { Study measured fatigue/sleepiness in participants } \\
\text { post-stroke and at the time of study data collection } \\
\text { (e.g., not retrospective data from chart review). }\end{array}$ & If no, study was excluded. \\
\hline Research type & $\begin{array}{l}\text { Study design is quantitative, qualitative, or mixed } \\
\text { methods. }\end{array}$ & If no, study was excluded. \\
\hline
\end{tabular}


Table 3. Critical appraisal criteria

NOTE: Given the nature of a scoping review, the focus of critical appraisal was only to evaluate the methodological quality of the selected studies' inclusion/exclusion criteria.

\begin{tabular}{|l|l|l|l|}
\hline Criterion & $\begin{array}{l}\text { Type of } \\
\text { Bias }\end{array}$ & Scale & How Applied \\
\hline $\begin{array}{l}\text { Participant characteristics are adequately } \\
\text { described to determine whether or not } \\
\text { aphasia/speech/language/communication } \\
\text { disorder was included or excluded from the study. }\end{array}$ & $\begin{array}{l}\text { Reporting } \\
\text { bias }\end{array}$ & $\begin{array}{l}1 \text { (yes) } \\
2 \text { (no) }\end{array}$ & If no, study was excluded. \\
- $\begin{array}{l}\text { Defined as a discussion of } \\
\text { inclusion/exclusion criteria with enough } \\
\text { detail to include some mention of } \\
\text { aphasia/speech/language/communication } \\
\text { disorder. }\end{array}$ & & & \\
\hline
\end{tabular}


Table 4. Frequency of tests used to identify communication disorders. Note: Studies that used multiple measures and are represented more than once on this table, whereas studies that used other methods (e.g., previous diagnosis) are not included here.

\begin{tabular}{|c|c|c|}
\hline & & \# studies reporting \\
\hline \multirow[t]{10}{*}{$\begin{array}{r}\text { Specific Language and } \\
\text { Aphasia Tests } \\
\end{array}$} & Token Test (TT) & 8 \\
\hline & $\begin{array}{l}\text { Frenchay Aphasia Screening Test } \\
\text { (FAST) }\end{array}$ & 2 \\
\hline & Boston Naming Test (BNT) & 1 \\
\hline & Brief Aphasia Checklist (BACL) & 1 \\
\hline & The Aphasia Scale (AS) & 1 \\
\hline & $\begin{array}{l}\text { Boston Diagnostic Aphasia Exam } \\
\text { (BDAE) }\end{array}$ & 1 \\
\hline & $\begin{array}{l}\text { Sheffield Screening Test for } \\
\text { Acquired Language Disorders } \\
\text { (SSTALD) }\end{array}$ & 1 \\
\hline & Chapman Reading Task (CRT) & 1 \\
\hline & Ullevål Aphasia Screening Test & 1 \\
\hline & Western Aphasia Battery & 1 \\
\hline \multirow[t]{5}{*}{$\begin{array}{r}\text { General Stroke } \\
\text { Screening Measures } \\
\end{array}$} & NIH Stroke Scale (NIH) & 8 \\
\hline & Scandinavian Stroke Scale (ScSS) & 1 \\
\hline & Stroke Impact Scale (SIS) & 1 \\
\hline & $\begin{array}{l}\text { Stroke Impairment Assessment Set } \\
\text { (SIAS) }\end{array}$ & 1 \\
\hline & Stroke Levity Scale (SLS) & 1 \\
\hline
\end{tabular}


Table 5. Frequency of sleepiness/fatigue measures. Note: Studies that used multiple measures are represented more than once on this table, whereas other studies that did not use published measures are not included here.

\begin{tabular}{|c|c|c|}
\hline & & \# studies reporting \\
\hline \multirow[t]{2}{*}{ Commonly used ( $10 \%$ or more) } & Fatigue Severity Scale (FSS) & 50 \\
\hline & Epworth Sleepiness Scale (ESS) & 21 \\
\hline \multirow[t]{4}{*}{ Rarely used (3-9\%) } & Multidimensional Fatigue Inventory (MFI) & 15 \\
\hline & Fatigue Assessment Scale (FAS) & 17 \\
\hline & Visual Analog Fatigue Scale (VAFS) & 9 \\
\hline & Checklist of Individual Strength (CISSF) & 6 \\
\hline \multirow[t]{14}{*}{ Very rarely used (fewer than $3 \%$ ) } & $\begin{array}{l}\text { RAND 36-Item Health Survey Questionnaire } \\
\text { (RAND) }\end{array}$ & 5 \\
\hline & Stanford Sleepiness Scale (SSS) & 5 \\
\hline & Profile of Mood States (POMS) & 4 \\
\hline & Stroke-Specific Quality of Life Scale (SS-QOL) & 3 \\
\hline & Fatigue Impact Scale (FIS) & 3 \\
\hline & Short Form Health Survey (SFHS) & 2 \\
\hline & $\begin{array}{l}\text { Utrecht Scale for Evaluation of Clinical } \\
\text { Rehabilitation (USER) }\end{array}$ & 2 \\
\hline & Berlin Questionnaire (BQ) & 2 \\
\hline & $\begin{array}{l}\text { Assessment Tool for Long-Term } \\
\text { Consequences After Stroke (ACAS) }\end{array}$ & 1 \\
\hline & Barthel Index (BI) & 1 \\
\hline & Borg Scale (BS) & 1 \\
\hline & Canadian Neurological Scale (CAN) & 1 \\
\hline & Detection Fatigue List (DLF) & 1 \\
\hline & Goteborg Quality of Life Instrument (GQLI) & 1 \\
\hline & $\begin{array}{l}\text { Greater Manchester Stroke Assessment Tool } \\
\text { (GM-SAT) }\end{array}$ & 1 \\
\hline & $\begin{array}{l}\text { Newcastle Stroke-Specific Quality of Life } \\
\text { Measure (NEWSQOL) }\end{array}$ & 1 \\
\hline & Riks-Stroke Questionnaire (RSQ) & 1 \\
\hline & $\begin{array}{l}\text { Self-Assessment Questionnaire for Mental } \\
\text { Fatigue (SQfMF) }\end{array}$ & 1 \\
\hline & $\begin{array}{l}\text { Sheffield Profile for Assessment and Referral } \\
\text { to Care (SPARC) }\end{array}$ & 1 \\
\hline & Stroke Survivor Needs Survey (SSNS) & 1 \\
\hline & Karolinska Sleepiness Scale (KSS) & 1 \\
\hline & Mental Fatigue Scale & 1 \\
\hline & PROMIS Fatigue Scale & 1 \\
\hline
\end{tabular}


Figure 1. Flow diagram of study selection.

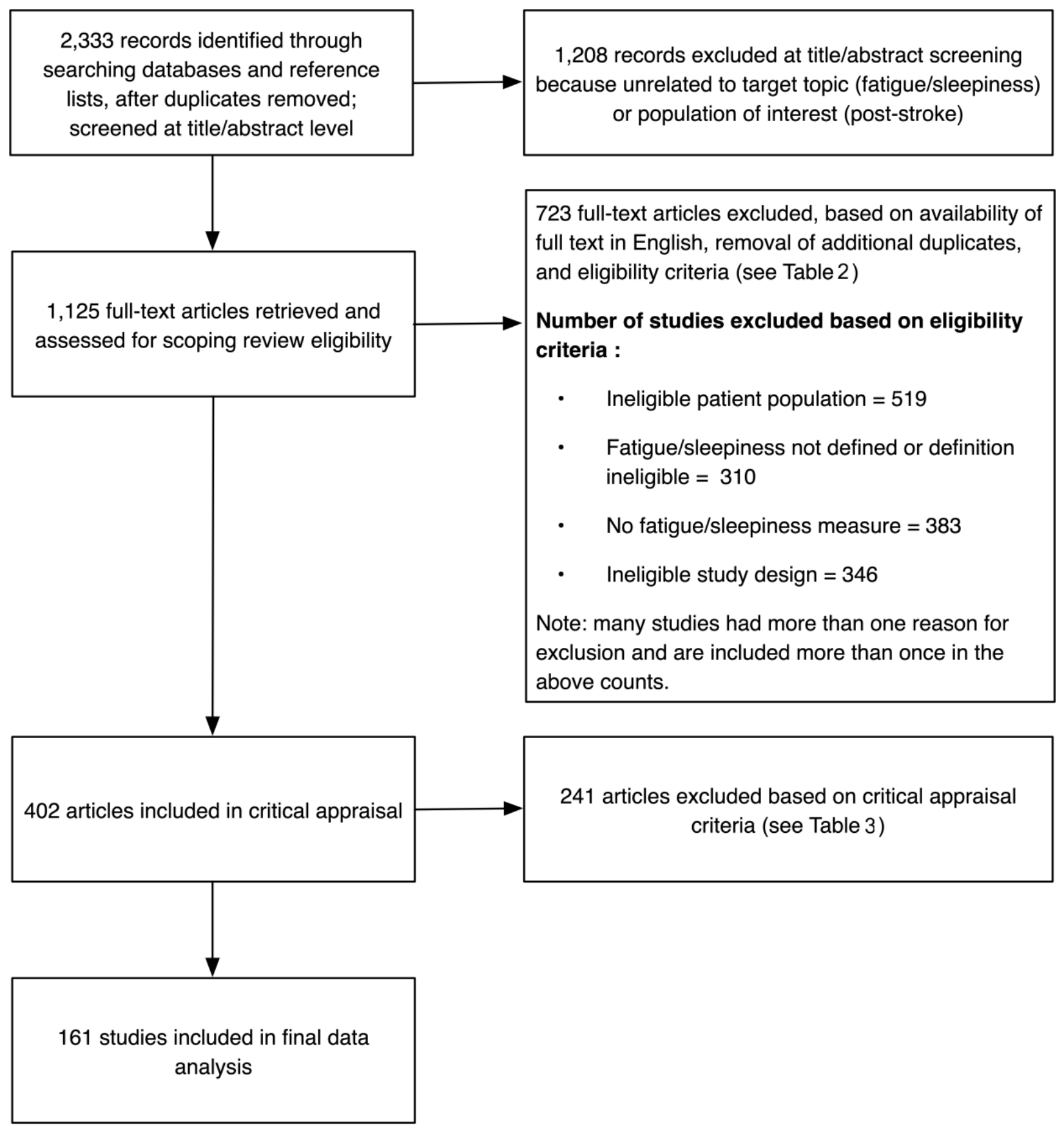


Figure 2. Percentage of studies that specifically included and excluded communication disorders (A), methods of identifying communication disorders (B), purposes of measuring fatigue (C), and methods of measuring fatigue (D).

$$
\text { A }
$$

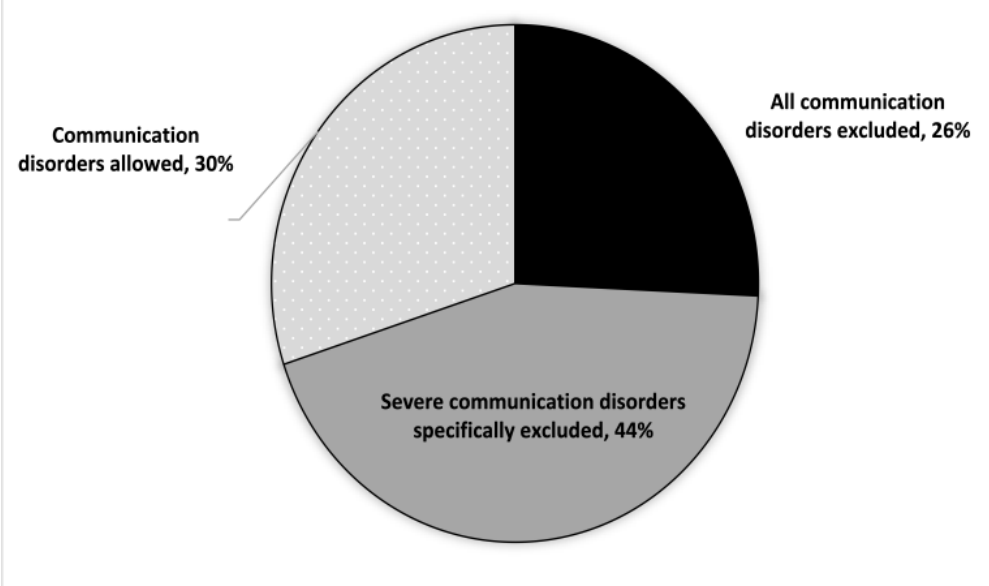

C

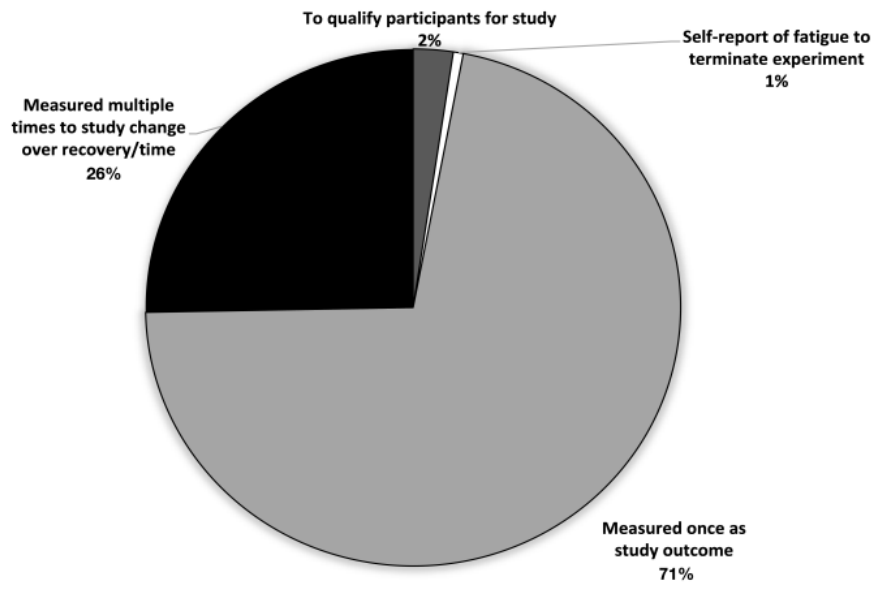

B

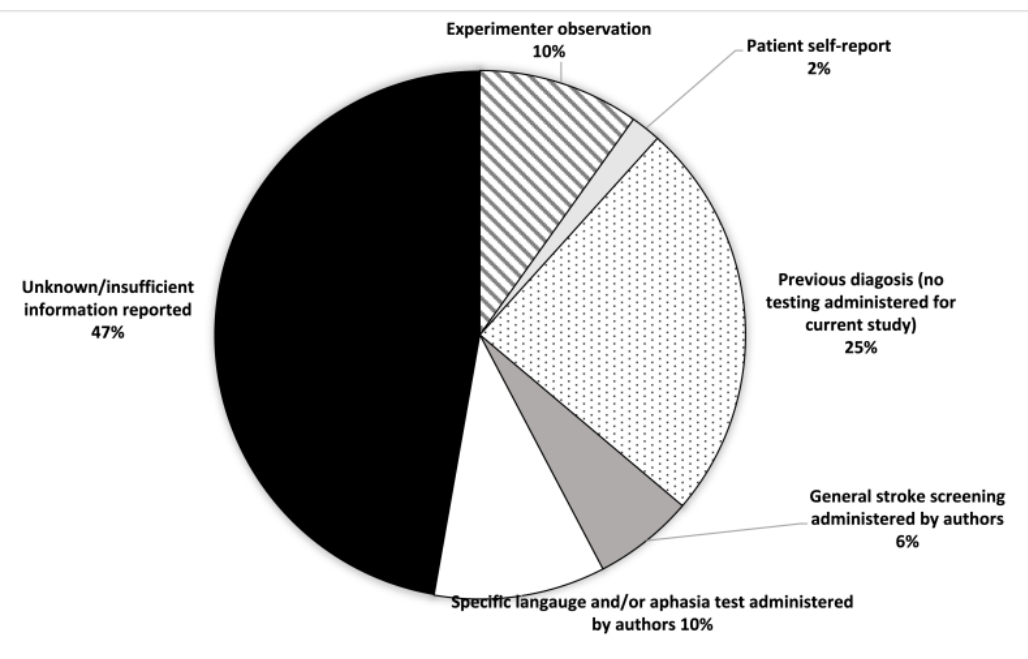

D

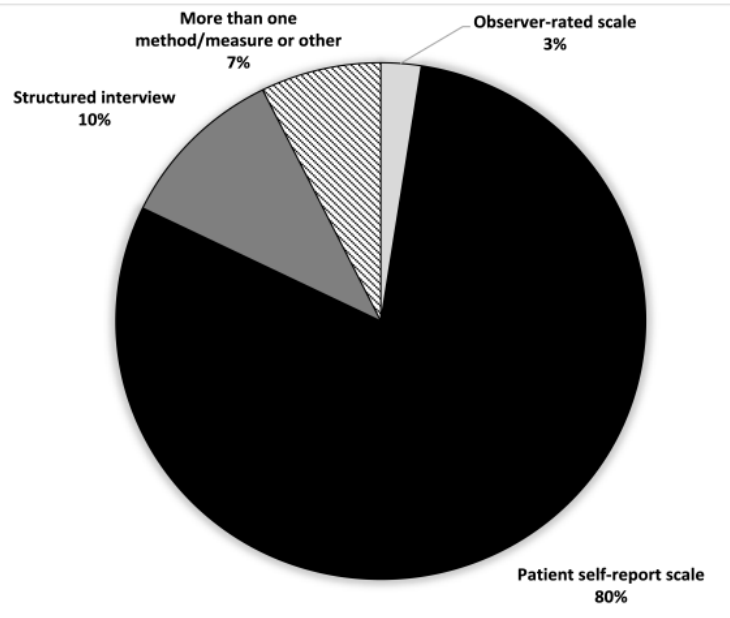




\section{Appendix A}

PubMed search strategy

\begin{tabular}{|l|l|}
\hline Number & Search terms \\
\hline$\# 1$ & Search fatigue[MH] \\
\hline$\# 2$ & $\begin{array}{l}\text { Search ((sleepy[TIAB] OR sleepiness[TIAB] OR drows*[TIAB] OR drowsy[TIAB] OR } \\
\text { drowsiness[TIAB] OR tired[TIAB] OR tiredness[TIAB] OR fatigue[TIAB] OR fatigued[TIAB] } \\
\text { OR fatiguing[TIAB])) }\end{array}$ \\
\hline$\# 3$ & Search \#1 OR \#2 \\
\hline$\# 4$ & Search ((intracranial hemorrhages[MH]) OR brain ischemia[MH]) OR stroke[MH] \\
\hline$\# 5$ & $\begin{array}{l}\text { Search ((((stroke[TIAB]) OR strokes[TIAB]) OR "post stroke"[TIAB]) OR "post-stroke"[TIAB]) } \\
\text { OR poststroke[TIAB] }\end{array}$ \\
\hline$\# 6$ & $\begin{array}{l}\text { Search (("post stroke fatigue"[TW]) OR "post-stroke fatigue"[TW]) OR "poststroke } \\
\text { fatigue"[TW] }\end{array}$ \\
\hline$\# 7$ & Search \#4 OR \#5 OR \#6 \\
\hline$\# 8$ & Search \#3 AND \#7 \\
\hline$\# 9$ & $\begin{array}{l}\text { Search ("stroke rate"[TIAB] OR "stroke volume"[TIAB] OR swim[TIAB] OR swimming[TIAB] } \\
\text { OR "muscle fatigue"[TIAB] OR "fatigue of materials"[TIAB] OR "heat stroke"[TIAB] OR } \\
\text { heatstroke[TIAB] OR "sun stroke"[TIAB] OR "sunstroke"[TIAB]) }\end{array}$ \\
\hline$\# 10$ & Search \#8 NOT \#9 \\
\hline
\end{tabular}




\section{Appendix B}

Data extracted from studies that allowed persons with communication disorders (A); studies that excluded persons with communication disorders (B); and studies that excluded persons with severe communication disorders (C). Full references for these studies are included as Appendix C.

A

\begin{tabular}{|c|c|c|c|c|c|c|c|c|}
\hline Authors & $\begin{array}{l}\text { Publication } \\
\text { Year }\end{array}$ & $\begin{array}{l}\text { General } \\
\text { Study } \\
\text { Design }\end{array}$ & $\begin{array}{l}\text { Sample } \\
\text { Source }\end{array}$ & $\begin{array}{l}\text { Method } \\
\text { to } \\
\text { Measure } \\
\text { Fatigue }\end{array}$ & $\begin{array}{c}\text { Purpose } \\
\text { of } \\
\text { Fatigue } \\
\text { Measure }\end{array}$ & $\begin{array}{c}\text { Method } \\
\text { to } \\
\text { Identify } \\
\text { CD }\end{array}$ & $\begin{array}{l}\text { Inclusion } \\
\text { or } \\
\text { Exclusion } \\
\text { of PWCD }\end{array}$ & $\begin{array}{c}\text { Verified } \\
\text { Inclusion } \\
\text { of PWCD }\end{array}$ \\
\hline Alshaer, et al. & 2018 & $\overline{I I}$ & $\overline{\mathrm{RC}}$ & 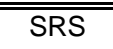 & Cha & 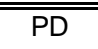 & ALLOW & $\overline{\mathrm{NR}}$ \\
\hline Andersen et al. & 2012 & D & $\mathrm{H}$ & SRS & Cha & PD & ALLOW & Y \\
\hline Andrew, et al. & 2014 & D & C & SRS & Out & PSR & ALLOW & Y \\
\hline Appelros & 2006 & D & M & SI & Out & GSS & ALLOW & Y \\
\hline Bassetti, et al. & 1999 & D & $\mathrm{H}$ & SRS & Out & GSS & ALLOW & NR \\
\hline Beaver, et al. & 2016 & 1 & $\mathrm{H}$ & SRS & Cha & PD & ALLOW & NR \\
\hline Benbir, et al. & 2012 & 1 & $\mathrm{H}$ & SRS & Cha & GSS & ALLOW & Y \\
\hline Bernhardt, et al. & 2008 & 1 & $\mathrm{H}$ & SRS & Out & EO & ALLOW & $\mathrm{Y}$ \\
\hline Broussy, et al. & 2019 & $\mathrm{D}$ & $\mathrm{H}$ & SRS & Out & NR & ALLOW & Y \\
\hline Bruhwyler, et al. & 1997 & 1 & $\mathrm{H}$ & ORS & Cha & EO & ALLOW & $\mathrm{Y}$ \\
\hline Buck, et al. & 2004 & D & M & M & Out & GSS & ALLOW & Y \\
\hline Burton, et al. & 2010 & D & $\mathrm{H}$ & SRS & Out & PSR & ALLOW & Y \\
\hline Dawes, et al. & 2006 & D & $\mathrm{RC}$ & M & Out & SLAT & ALLOW & $\mathrm{Y}$ \\
\hline Fens, et al. & 2015 & D & C & $\mathrm{SI}$ & Cha & PD & ALLOW & Y \\
\hline Flinn, et al. & 2010 & D & C & $\mathrm{SI}$ & Out & PD & ALLOW & $\mathrm{Y}$ \\
\hline Glader, et al. & 2002 & D & C & SRS & Out & PSR & ALLOW & Y \\
\hline $\begin{array}{r}\text { Groeneveld, et } \\
\text { al. }\end{array}$ & 2019 & D & $\mathrm{RC}$ & SRS & Cha & SLAT & ALLOW & $\mathrm{Y}$ \\
\hline Harris, et al. & 2009 & 1 & $\mathrm{H}$ & SRS & Out & PD & ALLOW & NR \\
\hline Hoang, et al. & 2012 & D & $\mathrm{RC}$ & M & Out & EO & ALLOW & Y \\
\hline Hofer, et al. & 2014 & 1 & C & SRS & Cha & SLAT & ALLOW & Y \\
\hline Kristensen, et al. & 2016 & D & C & SRS & Out & PD & ALLOW & Y \\
\hline Kruithof, et al. & 2016 & D & $\mathrm{RC}$ & M & Cha & PD & ALLOW & $\mathrm{Y}$ \\
\hline Magee, et al. & 2002 & I & M & ORS & Cha & PD & ALLOW & NR \\
\hline
\end{tabular}




\begin{tabular}{|c|c|c|c|c|c|c|c|c|}
\hline Mayo, et al. & 2004 & $\mathrm{D}$ & C & SRS & Out & NR & ALLOW & NR \\
\hline Michael, et al. & 2006 & $\mathrm{D}$ & C & M & Out & GSS & ALLOW & NR \\
\hline Michael, et al. & 2007 & $\mathrm{D}$ & C & SRS & Out & PD & ALLOW & NR \\
\hline Morsund, et al. & 2019 & $\mathrm{D}$ & $\mathrm{H}$ & SRS & Out & SLAT & ALLOW & NR \\
\hline Mutai, et al. & 2017 & $\mathrm{D}$ & $\mathrm{H}$ & SRS & Out & GSS & ALLOW & $\mathrm{Y}$ \\
\hline Naess, et al. & 2012 & $\mathrm{D}$ & $\mathrm{H}$ & SRS & Out & PD & ALLOW & $\mathrm{Y}$ \\
\hline Nguyen, et al. & 2019 & 1 & $\mathrm{RC}$ & SRS & Qual & NR & ALLOW & NR \\
\hline Oliveira, et al. & 2018 & $\mathrm{D}$ & $\mathrm{H}$ & SRS & Out & NR & ALLOW & $\mathrm{Y}$ \\
\hline Parra, et al. & 2015 & I & $\mathrm{H}$ & SRS & Out & PD & ALLOW & $\mathrm{Y}$ \\
\hline Riley et al. & 2019 & $\mathrm{D}$ & C & SRS & Out & SLAT & ALLOW & $\mathrm{Y}$ \\
\hline Ryan, et al. & 2000 & $D$ & $\mathrm{C}$ & SRS & Term & PD & ALLOW & $\mathrm{NR}$ \\
\hline Ryan, et al. & 2011 & 1 & $\mathrm{RC}$ & M & Cha & PD & ALLOW & NR \\
\hline Sarfo, et al. & 2018 & I & $\mathrm{H}$ & SRS & Out & GSS & ALLOW & NR \\
\hline Sico, et al. & 2017 & I & $\mathrm{H}$ & M & Out & PD & ALLOW & NR \\
\hline $\begin{array}{r}\text { Siengsukon, et } \\
\text { al. }\end{array}$ & 2009 & 1 & M & SRS & Cha & PD & ALLOW & $Y$ \\
\hline Simpson, et al. & 2018 & $\mathrm{D}$ & $\mathrm{RC}$ & SRS & Out & PD & ALLOW & $Y$ \\
\hline Skånér, et al. & 2007 & $\mathrm{D}$ & C & SRS & Out & PD & ALLOW & NR \\
\hline Ten Brink, et al. & 2017 & $D$ & $\mathrm{RC}$ & SRS & Out & PD & ALLOW & $\mathrm{NR}$ \\
\hline Tistad, et al. & 2012 & $\mathrm{D}$ & $\mathrm{H}$ & $\mathrm{SI}$ & Out & GSS & ALLOW & $Y$ \\
\hline $\begin{array}{r}\text { van de Port, et } \\
\text { al. }\end{array}$ & 2006 & $\mathrm{D}$ & $\mathrm{RC}$ & SRS & Out & SLAT & ALLOW & NR \\
\hline Van Wijk, et al. & 2006 & $\mathrm{D}$ & $\mathrm{RC}$ & SRS & Out & SLAT & ALLOW & $\mathrm{Y}$ \\
\hline $\begin{array}{r}\text { Van Zandvoort, } \\
\text { et al. }\end{array}$ & 1998 & $\mathrm{D}$ & $\mathrm{H}$ & SI & Out & SLAT & ALLOW & NR \\
\hline Vock, et al. & 2002 & $\mathrm{D}$ & $\mathrm{H}$ & SRS & $\begin{array}{l}\text { Qual; } \\
\text { Cha }\end{array}$ & PD & ALLOW & $Y$ \\
\hline Walsh, et al. & 2015 & $\mathrm{D}$ & C & SRS & Out & PD & ALLOW & $\mathrm{Y}$ \\
\hline Westergren & 2008 & $\mathrm{D}$ & $\mathrm{H}$ & SRS & Out & PD & ALLOW & $Y$ \\
\hline Yang, et al. & 2013 & $\mathrm{D}$ & $\mathrm{RC}$ & SRS & Cha & PD & ALLOW & $Y$ \\
\hline
\end{tabular}




\begin{tabular}{|c|c|c|c|c|c|c|c|c|}
\hline Authors & $\begin{array}{l}\text { Publication } \\
\text { Year }\end{array}$ & $\begin{array}{c}\text { General } \\
\text { Study } \\
\text { Design }\end{array}$ & $\begin{array}{l}\text { Sample } \\
\text { Source }\end{array}$ & $\begin{array}{l}\text { Method } \\
\text { to } \\
\text { Measure } \\
\text { Fatigue }\end{array}$ & $\begin{array}{c}\text { Purpose } \\
\text { of } \\
\text { Fatigue } \\
\text { Measure }\end{array}$ & $\begin{array}{l}\text { Method } \\
\text { to } \\
\text { Identify } \\
\text { CD }\end{array}$ & $\begin{array}{l}\text { Inclusion or } \\
\text { Exclusion of } \\
\text { PWCD }\end{array}$ & $\begin{array}{c}\text { Verified } \\
\text { Inclusion } \\
\text { of PWCD }\end{array}$ \\
\hline Badaru, et al. & 2013 & $\bar{D}$ & $\overline{\mathrm{H}}$ & SRS & Out & $\overline{P P D}$ & $\overline{E X C L}$ & $\overline{\mathrm{NR}}$ \\
\hline Chen, et al. & 2018 & D & $\mathrm{H}$ & SRS & Out & PD & EXCL & NR \\
\hline Chestnut & 2011 & D & $\mathrm{H}$ & SRS & Out & NR & EXCL & NR \\
\hline $\begin{array}{r}\text { Dharmakulaseelan, } \\
\text { et al. }\end{array}$ & 2019 & 1 & $\mathrm{C}$ & SRS & Out & NR & EXCL & NR \\
\hline Drummond, et al. & 2017 & D & $\mathrm{H}$ & SRS & Cha & NR & EXCL & NR \\
\hline Graber, et al. & 2019 & D & $\mathrm{H}$ & SRS & Out & NR & EXCL & NR \\
\hline Herron, et al. & 2018 & 1 & C & SRS & Out & NR & EXCL & NR \\
\hline Hubacher, et al. & 2012 & D & $\mathrm{RC}$ & SRS & Out & EO & EXCL & NR \\
\hline Kellett, et al. & 2014 & D & $\mathrm{RC}$ & SRS & Out & PD & EXCL & NR \\
\hline Kim, et al. & 2017 & D & $\mathrm{H}$ & SRS & Out & NR & EXCL & NR \\
\hline Kozlowski, et al. & 2015 & D & $\mathrm{C}$ & ORS & Out & NR & EXCL & NR \\
\hline Lamb, et al. & 2013 & D & $\mathrm{H}$ & SRS & Out & SLAT & EXCL & NR \\
\hline Lau, et al. & 2017 & D & $\mathrm{H}$ & SRS & Cha & NR & EXCL & NR \\
\hline Lynch, et al. & 2007 & D & $\mathrm{RC}$ & M & Out & NR & EXCL & NR \\
\hline Maris, et al. & 2018 & I & $\mathrm{RC}$ & SRS & Cha & NR & EXCL & NR \\
\hline Marsh, et al. & 2018 & D & $\mathrm{H}$ & SRS & Cha & NR & EXCL & NR \\
\hline Nakase, et al. & 2016 & D & $\mathrm{H}$ & SRS & Cha & NR & EXCL & NR \\
\hline Pajediene, et al. & 2020 & D & $\mathrm{H}$ & SRS & Out & NR & EXCL & NR \\
\hline Park, et al. & 2009 & D & C & SRS & Out & NR & EXCL & NR \\
\hline Parks, et al. & 2012 & D & $\mathrm{H}$ & SRS & Out & NR & EXCL & NR \\
\hline Patel, et al. & 2018 & 1 & $\mathrm{H}$ & SRS & Cha & NR & EXCL & NR \\
\hline $\begin{array}{r}\text { Ramirez-Moreno, } \\
\text { et al. }\end{array}$ & 2019 & D & $\mathrm{H}$ & SRS & Cha & PD & EXCL & NR \\
\hline Redgrave, et al. & 2018 & I & C & SRS & Out & NR & EXCL & NR \\
\hline Reeves, et al. & 2014 & D & $\mathrm{H}$ & M & Out & NR & EXCL & NR \\
\hline Rothwell, et al. & 2013 & D & C & SI & Out & NR & EXCL & $Y^{*}$ \\
\hline Saengsuwan, et al. & 2014 & D & $\mathrm{H}$ & SRS & Out & NR & EXCL & NR \\
\hline Schepers, et al. & 2006 & D & $\mathrm{RC}$ & SRS & Out & NR & EXCL & NR \\
\hline Schepers, et al. & 2009 & D & $\mathrm{RC}$ & SRS & Out & PD & EXCL & NR \\
\hline
\end{tabular}




$\begin{array}{rcccccccc}\begin{array}{r}\text { Shina et al. } \\ \text { Suh, et al. }\end{array} & 2019 & \text { D } & \text { H } & \text { SRS } & \text { Out } & \text { EO } & \text { EXCL } & \text { NR } \\ \begin{array}{r}\text { Tang, Lu, Mok, et } \\ \text { al. }\end{array} & 2011 & \text { D } & \text { H } & \text { SRS } & \text { Out } & \text { NR } & \text { EXCL } & \text { NR } \\ \begin{array}{r}\text { Tang, Lu, Liang, et } \\ \text { al. }\end{array} & 2011 & \text { D } & \text { H } & \text { SRS } & \text { Out } & \text { NR } & \text { EXCL } & \text { NR } \\ \begin{aligned} \text { Tang, et al. } \\ 2013\end{aligned} & \text { D } & \text { H } & \text { SRS } & \text { Out } & \text { SLAT } & \text { EXCL } & \text { NR } \\ \begin{array}{r}\text { Tang, et al. } \\ \text { van de Port, }\end{array} & 2015 a & \text { D } & \text { H } & \text { SRS } & \text { Out } & \text { NR } & \text { EXCL } & \text { NR } \\ \text { Kwakkel, Bruin, et } \\ \text { al. }\end{array}$

C

\begin{tabular}{rcccccccc}
\hline Authors & $\begin{array}{c}\text { Publication } \\
\text { Year }\end{array}$ & $\begin{array}{c}\text { General } \\
\text { Study } \\
\text { Design }\end{array}$ & $\begin{array}{c}\text { Sample } \\
\text { Source }\end{array}$ & $\begin{array}{c}\text { Method } \\
\text { to } \\
\text { Measure } \\
\text { Fatigue }\end{array}$ & $\begin{array}{c}\text { Purpose } \\
\text { of } \\
\text { Fatigue } \\
\text { Measure }\end{array}$ & $\begin{array}{c}\text { Method } \\
\text { to } \\
\text { Identify } \\
\text { CD }\end{array}$ & $\begin{array}{c}\text { Inclusion } \\
\text { or } \\
\text { Exclusion } \\
\text { of PWCD }\end{array}$ & $\begin{array}{c}\text { Verified } \\
\text { Inclusion } \\
\text { of PCD }\end{array}$ \\
\hline \hline Aaronson, et al. & 2015 & D & RC & SRS & Out & PD & S-EXCL & NR \\
Aaronson, et al. & 2016 & I & RC & SRS & Cha & NR & S-EXCL & NR \\
Bakken, et al. & 2012 & D & H & SRS & Cha & PD & S-EXCL & NR \\
Barbour, et al. & 2012 & D & H & M & Out & NR & S-EXCL & NR \\
Başkurt, et al. & 2017 & D & H & SRS & Out & NR & S-EXCL & NR \\
Bezeij, et al. & 2016 & I & RC & SRS & Cha & NR & S-EXCL & NR \\
Byun, et al. & 2020 & D & C & SRS & Out & NR & S-EXCL & NR \\
Carlsson, et al. & 2004 & D & NR & SI & Out & EO & S-EXCL & NR \\
Carlsson, et al. & 2009 & D & H & SI & Out & NR & S-EXCL & NR \\
Chen, et al. & 2015 & D & H & SI & Out & NR & S-EXCL & NR \\
Choi-Kwon, et al. & 2005 & D & RC & SRS & Out & NR & S-EXCL & Y
\end{tabular}




\begin{tabular}{|c|c|c|c|c|c|c|c|c|}
\hline Choi-Kwon, et al. & 2007 & 1 & $\mathrm{RC}$ & SRS & Out & NR & S-EXCL & NR \\
\hline $\begin{array}{r}\text { Choi-Kwon, Choi, et } \\
\text { al. }\end{array}$ & 2017 & $\mathrm{D}$ & $\mathrm{H}$ & SRS & Out & NR & S-EXCL & NR \\
\hline Choi-Kwon, Ko, et al. & 2017 & $\mathrm{D}$ & $\mathrm{H}$ & SRS & Out & NR & S-EXCL & NR \\
\hline Christensen, et al. & 2008 & $\mathrm{D}$ & $\mathrm{H}$ & SRS & Out & NR & S-EXCL & NR \\
\hline Dam, $\mathrm{H}$. & 2001 & $D$ & $\mathrm{H}$ & SRS & Out & PD & S-EXCL & NR \\
\hline de Coster, et al. & 2005 & $\mathrm{D}$ & $\mathrm{H}$ & SRS & Out & SLAT & S-EXCL & NR \\
\hline Delva, I & 2018 & $\mathrm{D}$ & NR & SRS & Cha & PD & S-EXCL & NR \\
\hline Douven, et al. & 2017 & $\mathrm{D}$ & $\mathrm{H}$ & SRS & Cha & NR & S-EXCL & NR \\
\hline Duncan, et al. & 2014 & $\mathrm{D}$ & M & SRS & Cha & NR & S-EXCL & NR \\
\hline Elgh, et al. & 2019 & $\mathrm{D}$ & $\mathrm{C}$ & SRS & Out & NR & S-EXCL & NR \\
\hline Emery & 2015 & 1 & C & SRS & $\begin{array}{l}\text { Qual; } \\
\text { Cha }\end{array}$ & PD & S-EXCL & NR \\
\hline Hsieh, et al. & 2011 & I & $\mathrm{H}$ & SRS & Cha & NR & S-EXCL & NR \\
\hline Huang, et al. & 2016 & 1 & $\mathrm{H}$ & SRS & $\begin{array}{l}\text { Qual; } \\
\text { Cha }\end{array}$ & NR & S-EXCL & NR \\
\hline Hummel, et al. & 2006 & $\mathrm{I}$ & NR & SRS & Cha & PD & S-EXCL & NR \\
\hline Ikuno, et al. & 2012 & I & $\mathrm{RC}$ & SRS & Out & NR & S-EXCL & NR \\
\hline Ingles, et al. & 1999 & $\mathrm{D}$ & $\mathrm{C}$ & SRS & Out & NR & S-EXCL & NR \\
\hline Khan, et al. & 2017 & $\mathrm{D}$ & $\mathrm{RC}$ & SRS & Out & NR & S-EXCL & $N R$ \\
\hline Kim, et al. & 2015 & $\mathrm{D}$ & $\mathrm{H}$ & SRS & Out & NR & S-EXCL & NR \\
\hline Kutlubaev, et al. & 2013 & $\mathrm{D}$ & 0 & SRS & Out & NR & S-EXCL & NR \\
\hline Lerdal, et al. & 2011 & $\mathrm{D}$ & $\mathrm{H}$ & SRS & Out & EO & S-EXCL & NR \\
\hline Lerdal, et al. & 2012 & $\mathrm{D}$ & $\mathrm{H}$ & SRS & Out & PD & S-EXCL & NR \\
\hline Liu & 2016 & $\mathrm{D}$ & $\mathrm{H}$ & SRS & Cha & SLAT & S-EXCL & NR \\
\hline Loureiro, et al. & 2017 & 1 & C & SRS & Out & NR & S-EXCL & NR \\
\hline Mazure, et al. & 2014 & $\mathrm{D}$ & $\mathrm{O}$ & SRS & Cha & NR & S-EXCL & NR \\
\hline McKechnie, et al. & 2010 & $\mathrm{D}$ & $\mathrm{H}$ & SRS & Out & NR & S-EXCL & $N R$ \\
\hline Mead, et al. & 2007 & $\mathrm{D}$ & $\mathrm{M}$ & SI & Out & EO & S-EXCL & NR \\
\hline $\begin{array}{r}\text { Medeiros, de Bruin, } \\
\text { Paiva, et al. }\end{array}$ & 2011 & $\mathrm{D}$ & $\mathrm{H}$ & SRS & Out & EO & S-EXCL & NR \\
\hline $\begin{array}{l}\text { Medeiros, de Bruin, } \\
\text { de Castro-Silva, et al. }\end{array}$ & 2011 & $\mathrm{D}$ & $\mathrm{H}$ & SRS & Out & NR & S-EXCL & NR \\
\hline
\end{tabular}




\begin{tabular}{|c|c|c|c|c|c|c|c|c|}
\hline Miller, et al. & 2013 & $\mathrm{D}$ & $M$ & SRS & Out & PD & S-EXCL & NR \\
\hline Palsdottir, et al. & 2020 & 1 & $\mathrm{H}$ & SRS & Out & NR & S-EXCL & NR \\
\hline Pihlaja, et al. & 2014 & $\mathrm{D}$ & $\mathrm{H}$ & SRS & Cha & SLAT & S-EXCL & NR \\
\hline Ponchel, et al. & 2016 & $\mathrm{D}$ & $\mathrm{H}$ & SRS & Cha & NR & S-EXCL & NR \\
\hline Röding, et al. & 2003 & $\mathrm{D}$ & NR & SI & Out & NR & S-EXCL & NR \\
\hline Rogeau, et al. & 2014 & $\mathrm{D}$ & $\mathrm{RC}$ & M & Out & SLAT & S-EXCL & NR \\
\hline Sarfo, et al. & 2017 & $\mathrm{D}$ & $\mathrm{RC}$ & SRS & Out & NR & S-EXCL & NR \\
\hline Smith, et al. & 2008 & $\mathrm{D}$ & $\mathrm{RC}$ & SRS & Out & NR & S-EXCL & NR \\
\hline Spalletta, et al. & 2005 & $\mathrm{D}$ & $\mathrm{H}$ & SRS & Out & EO & S-EXCL & NR \\
\hline Sterr, et al. & 2018 & $\mathrm{D}$ & $\mathrm{C}$ & SRS & Out & NR & S-EXCL & NR \\
\hline Stokes, et al. & 2011 & $D$ & C & SRS & Out & EO & S-EXCL & NR \\
\hline Tang, Chen, et al. & 2014 & $\mathrm{D}$ & $\mathrm{H}$ & SI & Cha & NR & S-EXCL & NR \\
\hline Tang, Liu, et al. & 2014 & $\mathrm{D}$ & $\mathrm{H}$ & SI & Out & NR & S-EXCL & NR \\
\hline Tang, et al. & $2015 b$ & $\mathrm{D}$ & $\mathrm{H}$ & SRS & Cha & NR & S-EXCL & NR \\
\hline Terroni, et al. & 2009 & $\mathrm{D}$ & $\mathrm{H}$ & SRS & Out & NR & S-EXCL & NR \\
\hline Thompson, et al. & 2009 & $\mathrm{D}$ & 0 & SI & Out & PD & S-EXCL & NR \\
\hline Türkbey, et al. & 2017 & 1 & $\mathrm{RC}$ & SRS & Cha & NR & S-EXCL & NR \\
\hline $\begin{array}{r}\text { van de Port, van den } \\
\text { Bos, et al. }\end{array}$ & 2007 & $\mathrm{D}$ & $\mathrm{RC}$ & SRS & Out & NR & S-EXCL & NR \\
\hline van de Port, et al. & 2008 & $\mathrm{D}$ & $\mathrm{C}$ & SRS & Out & EO & S-EXCL & NR \\
\hline van der Zee, et al. & 2013 & $\mathrm{D}$ & $\mathrm{RC}$ & ORS & Out & PD & S-EXCL & NR \\
\hline Van Rijsbergen, et al. & 2019 & $\mathrm{D}$ & $\mathrm{H}$ & SRS & Out & NR & S-EXCL & NR \\
\hline Van Rijsbergen, et al. & 2020 & $\mathrm{D}$ & $\mathrm{H}$ & SRS & Out & NR & S-EXCL & NR \\
\hline Wang, et al. & 2014 & $\mathrm{D}$ & $\mathrm{H}$ & SRS & Out & PD & S-EXCL & NR \\
\hline West, et al. & 2019 & I & $\mathrm{H}$ & SRS & Out & EO & S-EXCL & NR \\
\hline White, et al. & 2012 & $\mathrm{D}$ & $C$ & SI & Out & EO & S-EXCL & NR \\
\hline Widar, et al. & 2004 & $\mathrm{D}$ & $\mathrm{H}$ & SI & Out & NR & S-EXCL & NR \\
\hline Williams, et al. & 1999 & $\mathrm{D}$ & $\mathrm{H}$ & SI & Out & GSS & S-EXCL & Y \\
\hline $\begin{array}{l}\text { Winkens, Van } \\
\text { Heugten, Wade, et }\end{array}$ & 2009 & 1 & M & SRS & Out & NR & S-EXCL & NR \\
\hline
\end{tabular}




\begin{tabular}{rcccccccc}
$\begin{array}{r}\text { Winkens, Van } \\
\text { Heugten, Fasotti, et } \\
\text { al. }\end{array}$ & 2009 & D & RC & SRS & Out & EO & S-EXCL & NR \\
$\begin{array}{r}\text { Worthington, et al. } \\
2017\end{array}$ & D & H & M & Out & SLAT & S-EXCL & NR \\
Yayla, et al. & 2016 & D & O & SRS & Out & NR & S-EXCL & NR \\
Zhang, et al. & 2019 & D & H & SRS & Out & EO & S-EXCL & NR \\
\hline
\end{tabular}

$\mathrm{CD}=$ Communication disorder; $\mathrm{PWCD}=$ person with communication disorder;

D = Descriptive; I = Intervention;

$\mathrm{RC}=$ rehabilitation or outpatient clinic; $\mathrm{H}=$ hospital; $\mathrm{C}=$ community;

SRS = self-report scale; $\mathrm{SI}=$ structured interview; ORS = observer rated scale;

Out = study outcome; Cha = change over time; Qual = to qualify; Term = to terminate task;

$\mathrm{PD}=$ previous or physician's diagnosis; GSS = general stroke screening; EO = experimenter observation; SLAT = specific language/aphasia test; PSR = patient self-report;

ALLOW $=$ speech-languge disorder allowed; $E X C L=$ all speech-language disorders excluded; $\mathrm{S}-\mathrm{EXCL}=$ severe speechlanguage disorders excluded

$\mathrm{Y}=$ yes; $\mathrm{N}=\mathrm{no} ; \mathrm{NR}=$ Not reported; $\mathrm{M}=$ multiple sources or methods 


\section{Appendix C.}

References for articles listed in Appendix B

Aaronson, J. A., Hofman, W. F., Van Bennekom, C. A. M., Van Bezeij, T., Van Den Aardweg, J. G., Groet, E., Kylstra, W. A., \& Schmand, B. (2016). Effects of continuous positive airway pressure on cognitive and functional outcome of stroke patients with obstructive sleep apnea: A randomized controlled trial. Journal of Clinical Sleep Medicine, 12(4), 533-541. https://doi.org/10.5664/jcsm.5684

Aaronson, J. A., van Bennekom, C. A. M., Hofman, W. F., van Bezeij, T., van den Aardweg, J. G., Groet, E., Kylstra, W. A., \& Schmand, B. (2015). Obstructive Sleep Apnea is Related to Impaired Cognitive and Functional Status after Stroke. Sleep, 38(9), 1431-1437. https://doi.org/10.5665/sleep.4984

Alshaer, H., Pandya, A., Zivanovic, I., Carvalho, C. G., \& Ryan, C. M. (2018). The effect of continuous positive airway pressure on spectral encephalogram characteristics in stroke patients with obstructive sleep apnea. Respiratory Physiology \& Neurobiology, 249, 62-68. https://doi.org/10.1016/j.resp.2018.01.003

Andersen, G., Christensen, D., Kirkevold, M., \& Johnsen, S. P. (2012). Post-stroke fatigue and return to work: a 2-year follow-up. Acta Neurologica Scandinavica, 125(4), 248-253. https://doi.org/10.1111/j.1600-0404.2011.01557.x

Andrew, N. E., Kilkenny, M., Naylor, R., Purvis, T., Lalor, E., Moloczij, N., \& Cadilhac, D. A. (2014). Understanding Long-Term Unmet Needs in Australian Survivors of Stroke. International Journal of Stroke, 9(SA100), 106-112. https://doi.org/10.1111/ijs.12325

Appelros, P. (2006). Prevalence and predictors of pain and fatigue after stroke: a population-based study. International Journal of Rehabilitation Research, 29(4), 329-333. https://doi.org/10.1097/MRR.0b013e328010c7b8

Badaru, U. M., Ogwumike, O. O., Adeniyi, A. F., \& Olowe, O. O. (2013). Variation in Functional Independence among Stroke Survivors Having Fatigue and Depression. Neurology Research International, 2013, 1-6. https://doi.org/10.1155/2013/842980

Bakken, L. N., Kim, H. S., Finset, A., \& Lerdal, A. (2012). Stroke patients' functions in personal activities of daily living in relation to sleep and socio-demographic and clinical variables in the acute phase after first-time stroke and at six months of follow-up. Journal of Clinical Nursing, 21(13-14), 1886-1895. https://doi.org/10.1111/j.1365-2702.2011.04014.x

Barbour, V. L., \& Mead, G. E. (2012). Fatigue after Stroke: The Patient's Perspective. Stroke Research and Treatment, 2012, 1-6. https://doi.org/10.1155/2012/863031

Başkurt, F., Başkurt, Z., \& Günal, A. (2017). The effect of fatigue on the level of participation in a physiotherapy program of elderly acute stroke patients. Biomedical Research (India), 28(20), 90229027. https://www.scopus.com/inward/record.uri?eid=2-s2.085041680602\&partner $I D=40 \& m d 5=41824188765369 \mathrm{~d} 842 \mathrm{c} 50248 \mathrm{e} 311 \mathrm{fec} 0$ 
Bassetti, C., \& Aldrich, M. S. (1999). Sleep Apnea in Acute Cerebrovascular Diseases: Final Report on 128 Patients. Sleep, 22(2), 217-223. https://doi.org/10.1093/sleep/22.2.217

Beaver, T. M., Hedna, V. S., Khanna, A. Y., Miles, W. M., Price, C. C., Schmalfuss, I. M., Aalaei-Andabili, S. H., \& Waters, M. F. (2016). Thoracoscopic Ablation with Appendage Ligation versus Medical Therapy for Stroke Prevention a Proof-of-Concept Randomized Trial. Innovations: Technology and Techniques in Cardiothoracic and Vascular Surgery, 11(2), 99-105. https://doi.org/10.1097/imi.0000000000000226

Benbir, G., \& Karadeniz, D. (2012). A pilot study of the effects of non-invasive mechanical ventilation on the prognosis of ischemic cerebrovascular events in patients with obstructive sleep apnea syndrome. Neurological Sciences, 33(4), 811-818. https://doi.org/10.1007/s10072-011-0835-6

Bernhardt, J., Dewey, H., Thrift, A., Collier, J., \& Donnan, G. (2008). A Very Early Rehabilitation Trial for Stroke (AVERT). Stroke, 39(2), 390-396. https://doi.org/10.1161/STROKEAHA.107.492363

Bezeij, T., Aaronson, J., Bennekom, C., Hofman, W., Schmand, B., Aardweg, J., Groet, E., \& Kylst-Ra, W. (2016). Continuous positive airway pressure in stroke patients with obstructive sleep apnea: a randomized controlled trial. In Cerebrovascular diseases. (Vol. 41, p. 73). http://cochranelibrarywiley.com/o/cochrane/clcentral/articles/171/CN-01179171/frame.html

Broussy, S., Saillour-Glenisson, F., García-Lorenzo, B., Rouanet, F., Lesaine, E., Maugeais, M., Aly, F., Glize, B., Salamon, R., \& Sibon, I. (2019). Sequelae and Quality of Life in Patients Living at Home 1 Year After a Stroke Managed in Stroke Units. Frontiers in Neurology, 10(AUG). https://doi.org/10.3389/fneur.2019.00907

Bruhwyler, J., Van Dorpe, J., \& Géczy, J. (1997). Multicentric open-label study of the efficacy and tolerability of citicoline in the treatment of acute cerebral infarction. Current Therapeutic Research, 58(5), 309-316. https://doi.org/10.1016/S0011-393X(97)80028-8

Buck, D., Jacoby, A., Massey, A., Steen, N., Sharma, A., \& Ford, G. A. (2004). Development and Validation of NEWSQOL ${ }^{\circ}$, the Newcastle Stroke-Specific Quality of Life Measure. Cerebrovascular Diseases, 17(2-3), 143-152. https://doi.org/10.1159/000075783

Burton, C. R., Payne, S., Addington-Hall, J., \& Jones, A. (2010). The palliative care needs of acute stroke patients: a prospective study of hospital admissions. Age and Ageing, 39(5), 554-559. https://doi.org/10.1093/ageing/afq077

Byun, E., Kohen, R., Becker, K. J., Kirkness, C. J., Khot, S., \& Mitchell, P. H. (2020). Stroke impact symptoms are associated with sleep-related impairment. Heart and Lung, 49(2), 117-122. https://doi.org/10.1016/j.hrtlng.2019.10.010

Carlsson, G. E., Möller, A., \& Blomstrand, C. (2009). Managing an everyday life of uncertainty - A qualitative study of coping in persons with mild stroke. Disability and Rehabilitation, 31(10), 773782. https://doi.org/10.1080/09638280802638857 
Carlsson, G., Möller, A., \& Blomstrand, C. (2004). A qualitative study of the consequences of "hidden dysfunctions" one year after a mild stroke in persons \&amp;lt;?75 years. Disability and Rehabilitation, 26(23), 1373-1380. https://doi.org/10.1080/09638280400000211

Chen, C.-Y., Chen, C.-L., Yang, Y.-H., Ho, C.-H., \& Tseng, W.-C. (2018). Poststroke Depressive Symptoms Are Associated With Increased Oxidative Deoxyribonucleic Acid Damage. The Journal of Neuropsychiatry and Clinical Neurosciences, 30(2), 139-144. https://doi.org/10.1176/appi.neuropsych.17050108

Chen, Y.-K., Qu, J.-F., Xiao, W.-M., Li, W.-Y., Weng, H.-Y., Li, W., Liu, Y.-L., Luo, G.-P., Fang, X.-W., Ungvari, G. S., \& Xiang, Y.-T. (2015). Poststroke Fatigue: Risk Factors and its Effect on Functional Status and Health-Related Quality of Life. International Journal of Stroke, 10(4), 506-512. https://doi.org/10.1111/ijs.12409

Chestnut, T. J. (2010). Fatigue in stroke rehabilitation patients: a pilot study. Physiotherapy Research International, 16(3), n/a-n/a. https://doi.org/10.1002/pri.476

Choi-Kwon, S., Choi, S. H., Suh, M., Choi, S., Cho, K.-H., Nah, H.-W., Song, H., \& Kim, J. S. (2017). Musculoskeletal and central pain at 1 year post-stroke: associated factors and impact on quality of life. Acta Neurologica Scandinavica, 135(4), 419-425. https://doi.org/10.1111/ane.12617

Choi-Kwon, S., Choi, J., Kwon, S. U., Kang, D.-W., \& Kim, J. S. (2007). Fluoxetine Is Not Effective in the Treatment of Poststroke Fatigue: A Double-Blind, Placebo-Controlled Study. Cerebrovascular Diseases, 23(2-3), 103-108. https://doi.org/10.1159/000097045

Choi-Kwon, S., Han, S. W., Kwon, S. U., \& Kim, J. S. (2005). Poststroke Fatigue: Characteristics and Related Factors. Cerebrovascular Diseases, 19(2), 84-90. https://doi.org/10.1159/000082784

Choi-Kwon, S., Ko, M., Jun, S.-E., Kim, J., Cho, K.-H., Nah, H.-W., Song, H., \& Kim, J. S. (2017). Post-Stroke Fatigue May Be Associated with the Promoter Region of a Monoamine Oxidase A Gene Polymorphism. Cerebrovascular Diseases, 43(1-2), 54-58. https://doi.org/10.1159/000450894

Christensen, D., Johnsen, S. P., Watt, T., Harder, I., Kirkevold, M., \& Andersen, G. (2008). Dimensions of Post-Stroke Fatigue: A Two-Year Follow-Up Study. Cerebrovascular Diseases, 26(2), 134-141. https://doi.org/10.1159/000139660

Coster, L. de, Leentjens, A. F. G., Lodder, J., \& Verhey, F. R. J. (2005). The sensitivity of somatic symptoms in post-stroke depression: a discriminant analytic approach. International Journal of Geriatric Psychiatry, 20(4), 358-362. https://doi.org/10.1002/gps.1290

Dam, H. (2001). Depression in stroke patients 7 years following stroke. Acta Psychiatrica Scandinavica, 103(4), 287-293. https://doi.org/10.1034/j.1600-0447.2001.103004287.x

Dawes, H., Dawes, H., Scott, O. M., Roach, N. K., \& Wade, D. T. (2006). Exertional symptoms and exercise capacity in individuals with brain injury. Disability and Rehabilitation, 28(20), 1243-1250. https://doi.org/10.1080/09638280600554595 
Delva, I. (2018). Neurological and Neuroimaging Factors Associated with Post-Stroke Fatigue Over the Second Half Year After Acute Cerebrovascular Events. World of Medicine and Biology, 14(63), 023. https://doi.org/10.26724/2079-8334-2018-1-63-23-27

Dharmakulaseelan, L., Kirolos, N., Kamra, M., Armesto-Heys, A., Bouthillier, C., Runions, S., Linkewich, E., Murray, B. J., \& Boulos, M. I. (2019). Educating Stroke/TIA Patients about Obstructive Sleep Apnea after Stroke: A Randomized Feasibility Study. Journal of Stroke and Cerebrovascular Diseases, 28(11), 104317. https://doi.org/10.1016/j.jstrokecerebrovasdis.2019.104317

Douven, E., Köhler, S., Schievink, S. H. J., van Oostenbrugge, R. J., Staals, J., Verhey, F. R. J., \& Aalten, P. (2017). Temporal Associations between Fatigue, Depression, and Apathy after Stroke: Results of the Cognition and Affect after Stroke, a Prospective Evaluation of Risks Study. Cerebrovascular Diseases, 44(5-6), 330-337. https://doi.org/10.1159/000481577

Drummond, A., Hawkins, L., Sprigg, N., Ward, N. S., Mistri, A., Tyrrell, P., Mead, G. E., Worthington, E., \& Lincoln, N. B. (2017). The Nottingham Fatigue after Stroke (NotFAST) study: factors associated with severity of fatigue in stroke patients without depression. Clinical Rehabilitation, 31(10), 14061415. https://doi.org/10.1177/0269215517695857

Duncan, F., Greig, C., Lewis, S., Dennis, M., MacLullich, A., Sharpe, M., \& Mead, G. (2014). Clinically significant fatigue after stroke: A longitudinal cohort study. Journal of Psychosomatic Research, 77(5), 368-373. https://doi.org/10.1016/j.jpsychores.2014.06.013

Elgh, E., \& Hu, X. (2019). Dynamic Trajectory of Long-Term Cognitive Improvement Up to 10 Years in Young Community-Dwelling Stroke Survivors: A Cohort Study. Frontiers in Neurology, 10(FEB), 97. https://doi.org/10.3389/fneur.2019.00097

Emery, C. E. (2015). Relieving Post-Stroke Fatigue Using a Group-based Educational Training Approach. ProQuest Dissertations and Theses, 150. https://scholarscompass.vcu.edu/etd/3875

Fens, M., Beusmans, G., Limburg, M., van Hoef, L., van Haastregt, J., Metsemakers, J., \& van Heugten, C. (2015). A process evaluation of a stroke-specific follow-up care model for stroke patients and caregivers; a longitudinal study. BMC Nursing, 14(1), 3. https://doi.org/10.1186/s12912-014-00528

Flinn, N. A., \& Stube, J. E. (2010). Post-stroke fatigue: qualitative study of three focus groups. Occupational Therapy International, 17(2), 81-91. https://doi.org/10.1002/oti.286

Glader, E.-L., Stegmayr, B., \& Asplund, K. (2002). Poststroke Fatigue: a 2-year follow-up study of stroke patients in Sweden. Stroke, 33(5), 1327-1333.

https://doi.org/10.1161/01.STR.0000014248.28711.D6

Graber, M., Garnier, L., Duloquin, G., Mohr, S., Guillemin, S., Ramaget, O., Piver, A., Tainturier, C., BretLegrand, C., Delpont, B., Blanc-Labarre, C., Guéniat, J., Hervieu-Bègue, M., Osseby, G.-V., Giroud, M., \& Béjot, Y. (2019). Association Between Fatigue and Cognitive Impairment at 6 Months in Patients With Ischemic Stroke Treated With Acute Revascularization Therapy. Frontiers in Neurology, 10(AUG), 931. https://doi.org/10.3389/fneur.2019.00931 
Groeneveld, I. F., Goossens, P. H., van Meijeren-Pont, W., Arwert, H. J., Meesters, J. J. L., Rambaran Mishre, A. D., Van Vree, F., \& Vliet Vlieland, T. P. M. (2019). Value-Based Stroke Rehabilitation: Feasibility and Results of Patient-Reported Outcome Measures in the First Year After Stroke. Journal of Stroke and Cerebrovascular Diseases, 28(2), 499-512. https://doi.org/10.1016/j.jstrokecerebrovasdis.2018.10.033

Harris, J. E., Eng, J. J., Miller, W. C., \& Dawson, A. S. (2009). A Self-Administered Graded Repetitive Arm Supplementary Program (GRASP) Improves Arm Function During Inpatient Stroke Rehabilitation. Stroke, 40(6), 2123-2128. https://doi.org/10.1161/STROKEAHA.108.544585

Herron, K., Farquharson, L., Wroe, A., \& Sterr, A. (2018). Development and Evaluation of a Cognitive Behavioural Intervention for Chronic Post-Stroke Insomnia. Behavioural and Cognitive Psychotherapy, 46(6), 641-660. https://doi.org/10.1017/S1352465818000061

Hofer, H., Grosse Holtforth, M., Lüthy, F., Frischknecht, E., Znoj, H., \& Müri, R. M. (2014). The Potential of a Mindfulness-Enhanced, Integrative Neuro-psychotherapy Program for Treating Fatigue Following Stroke: A Preliminary Study. Mindfulness, 5(2), 192-199. https://doi.org/10.1007/s12671-012-0167-5

Hsieh, Y., Wu, C., Liao, W., Lin, K., Wu, K., \& Lee, C. (2011). Effects of Treatment Intensity in Upper Limb Robot-Assisted Therapy for Chronic Stroke. Neurorehabilitation and Neural Repair, 25(6), 503-511. https://doi.org/10.1177/1545968310394871

Huang, Z., Zhan, J., Pan, R., Guo, Y., He, M., Chen, H., \& Zhan, L. (2016). Effects of Bo's abdominal acupuncture on post-stroke fatigue: a pilot study. In G. Tian, T and Jiang, $Q$ and Liu, $Y$ and Burrage, $\mathrm{K}$ and Song, $\mathrm{J}$ and Wang, $\mathrm{Y}$ and $\mathrm{Hu}, \mathrm{X}$ and Morishita, $\mathrm{S}$ and $\mathrm{Zhu}, \mathrm{Q}$ and Wang (Ed.), 2016 IEEE International Conference on Bioinformatics and Biomedicine (BIBM) (pp. 1359-1362).

Hubacher, M., Calabrese, P., Bassetti, C., Carota, A., Stöcklin, M., \& Penner, I.-K. (2012). Assessment of Post-Stroke Fatigue: The Fatigue Scale for Motor and Cognitive Functions. European Neurology, 67(6), 377-384. https://doi.org/10.1159/000336736

Hummel, F., Voller, B., Celnik, P., Floel, A., Giraux, P., Gerloff, C., \& Cohen, L. (2006). Effects of brain polarization on reaction times and pinch force in chronic stroke. In BMC neuroscience (Vol. 7, p. 73). https://doi.org/https://doi.org/10.1186/1471-2202-7-73

Ikuno, K., Kawaguchi, S., Kitabeppu, S., Kitaura, M., Tokuhisa, K., Morimoto, S., Matsuo, A., \& Shomoto, K. (2012). Effects of peripheral sensory nerve stimulation plus task-oriented training on upper extremity function in patients with subacute stroke: a pilot randomized crossover trial. Clinical Rehabilitation, 26(11), 999-1009. https://doi.org/10.1177/0269215512441476

Ingles, J. L., Eskes, G. A., \& Phillips, S. J. (1999). Fatigue after stroke. Archives of Physical Medicine and Rehabilitation, 80(2), 173-178. https://doi.org/10.1016/S0003-9993(99)90116-8

Kellett, N., Drummond, A. E., Palmer, T., Munshi, S., \& Lincoln, N. B. (2014). Impact of transient ischaemic attack and minor stroke on daily life. International Journal of Therapy and Rehabilitation, 21(7), 318-323. https://doi.org/10.12968/ijtr.2014.21.7.318 
Khan, A., \& Delargy, M. (2017). Post stroke fatigue; point prevalence, characterization, associations and radiological correlation in a rehabilitation hospital. Irish Medical Journal, 110(10), 650.

https://www.scopus.com/inward/record.uri?eid=2-s2.0-

85038076502\&partnerID=40\&md5=ef88c8894a8061590aeabe1a5976cb73

Kim, J., Kim, Y., Yang, K. I., Kim, D., \& Kim, S. A. (2015). The Relationship Between Sleep Disturbance and Functional Status in Mild Stroke Patients. Annals of Rehabilitation Medicine, 39(4), 545. https://doi.org/10.5535/arm.2015.39.4.545

Kim, K. T., Moon, H.-J., Yang, J.-G., Sohn, S.-I., Hong, J.-H., \& Cho, Y. W. (2017). The prevalence and clinical significance of sleep disorders in acute ischemic stroke patients - a questionnaire study. Sleep and Breathing, 21(3), 759-765. https://doi.org/10.1007/s11325-016-1454-5

Kozlowski, A. J., Singh, R., Victorson, D., Miskovic, A., Lai, J.-S., Harvey, R. L., Cella, D., \& Heinemann, A. W. (2015). Agreement Between Responses From Community-Dwelling Persons With Stroke and Their Proxies on the NIH Neurological Quality of Life (Neuro-QoL) Short Forms. Archives of Physical Medicine and Rehabilitation, 96(11), 1986-1992.e14. https://doi.org/10.1016/j.apmr.2015.07.005

Kristensen, H. K., Tistad, M., Koch, L. von, \& Ytterberg, C. (2016). The Importance of Patient Involvement in Stroke Rehabilitation. PLOS ONE, 11(6), e0157149.

https://doi.org/10.1371/journal.pone.0157149

Kruithof, N., Van Cleef, M. H. M., Rasquin, S. M. C., \& Bovend'Eerdt, T. J. H. (2016). Screening Poststroke Fatigue; Feasibility and Validation of an Instrument for the Screening of Poststroke Fatigue throughout the Rehabilitation Process. Journal of Stroke and Cerebrovascular Diseases, 25(1), 188196. https://doi.org/10.1016/j.jstrokecerebrovasdis.2015.09.015

Kutlubaev, M. A., Shenkin, S. D., Farrall, A. J., Duncan, F. H., Lewis, S. J., Greig, C. A., Dennis, M. S., Wardlaw, J. M., Maclullich, A. M. J., \& Mead, G. E. (2013). CT and Clinical Predictors of Fatigue at One Month after Stroke . Cerebrovascular Diseases Extra , 3(1), 26-34. https://doi.org/10.1159/000347113

Lamb, F., Anderson, J., Saling, M., \& Dewey, H. (2013). Predictors of Subjective Cognitive Complaint in Postacute Older Adult Stroke Patients. Archives of Physical Medicine and Rehabilitation, 94(9), 1747-1752. https://doi.org/10.1016/j.apmr.2013.02.026

Lan Nguyen Hoang, C., Salle, J.-Y., Mandigout, S., Hamonet, J., Macian-Montoro, F., \& Daviet, J.-C. (2012). Physical Factors Associated With Fatigue After Stroke: An Exploratory Study. Topics in Stroke Rehabilitation, 19(5), 369-376. https://doi.org/10.1310/tsr1905-369

Lau, C. G., Tang, W. K., Liu, X. X., Liang, H. J., Liang, Y., Mok, V., Wong, A., Ungvari, G. S., Kutlubaev, M. A., \& Wong, K. S. (2017). Neuroticism and Fatigue 3 Months After Ischemic Stroke. Archives of Physical Medicine and Rehabilitation, 98(4), 716-721. https://doi.org/10.1016/j.apmr.2016.08.480

Lerdal, A., Bakken, L. N., Rasmussen, E. F., Beiermann, C., Ryen, S., Pynten, S., Drefvelin, Å. S., Dahl, A. M., Rognstad, G., Finset, A., Lee, K. A., \& Kim, H. S. (2011). Physical impairment, depressive 
symptoms and pre-stroke fatigue are related to fatigue in the acute phase after stroke. Disability and Rehabilitation, 33(4), 334-342. https://doi.org/10.3109/09638288.2010.490867

Lerdal, A., Lee, K. A., Bakken, L. N., Finset, A., \& Kim, H. S. (2012). The Course of Fatigue during the First 18 Months after First-Ever Stroke: A Longitudinal Study. Stroke Research and Treatment, 2012, 1-8. https://doi.org/10.1155/2012/126275

Liu, C.-H., Tsai, C.-H., Li, T.-C., Yang, Y.-W., Huang, W.-S., Lu, M.-K., Tseng, C.-H., Huang, H.-C., Chen, K.-F., Hsu, T.-S., Hsu, Y.-T., Tsai, C.-H., \& Hsieh, C.-L. (2016). Effects of the traditional Chinese herb Astragalus membranaceus in patients with poststroke fatigue: A double-blind, randomized, controlled preliminary study. Journal of Ethnopharmacology, 194, 954-962. https://doi.org/10.1016/j.jep.2016.10.058

Loureiro, A., Langhammer, B., GjÃ,vaag, T., Ihle-Hansen, H., \& Guarita-Souza, L. (2017). Skeletal muscle metabolism after stroke: A comparative study using treadmill and overground walking test. Journal of Rehabilitation Medicine, 49(7), 558-564. https://doi.org/10.2340/16501977-2255

Lynch, J., Mead, G., Greig, C., Young, A., Lewis, S., \& Sharpe, M. (2007). Fatigue after stroke: The development and evaluation of a case definition. Journal of Psychosomatic Research, 63(5), 539544. https://doi.org/10.1016/j.jpsychores.2007.08.004

Magee, W. L., \& Davidson, J. W. (2002). The Effect of Music Therapy on Mood States in Neurological Patients: A Pilot Study. Journal of Music Therapy, 39(1), 20-29. https://doi.org/10.1093/jmt/39.1.20

Maris, A., Coninx, K., Seelen, H., Truyens, V., De Weyer, T., Geers, R., Lemmens, M., Coolen, J., Stupar, S., Lamers, I., \& Feys, P. (2018). The impact of robot-mediated adaptive I-TRAVLE training on impaired upper limb function in chronic stroke and multiple sclerosis. Disability and Rehabilitation: Assistive Technology, 13(1), 1-9. https://doi.org/10.1080/17483107.2016.1278467

Marsh, E. B., Lawrence, E., Hillis, A. E., Chen, K., Gottesman, R. F., \& Llinas, R. H. (2018). Pre-stroke employment results in better patient-reported outcomes after minor stroke. Clinical Neurology and Neurosurgery, 165, 38-42. https://doi.org/10.1016/j.clineuro.2017.12.020

Mayo, N. E., Poissant, L., Ahmed, S., Finch, L., Higgins, J., Salbach, N. M., Soicher, J., \& Jaglal, S. (2004). Incorporating the International Classification of Functioning, Disability, and Health (ICF) into an Electronic Health Record to Create Indicators of Function: Proof of Concept Using the SF-12. Journal of the American Medical Informatics Association, 11(6), 514-522. https://doi.org/10.1197/jamia.M1462

Mazure, C. M., Weinberger, A. H., Pittman, B., Sibon, I., \& Swendsen, J. (2014). Gender and Stress in Predicting Depressive Symptoms Following Stroke. Cerebrovascular Diseases, 38(4), 240-246. https://doi.org/10.1159/000365838

McKechnie, F., Lewis, S., \& Mead, G. (2010). A pilot observational study of the association between fatigue after stroke and C-reactive protein. The Journal of the Royal College of Physicians of Edinburgh, 40(1), 9-12. https://doi.org/10.4997/JRCPE.2010.103 
Mead, G., Lynch, J., Greig, C., Young, A., Lewis, S., \& Sharpe, M. (2007). Evaluation of Fatigue Scales in Stroke Patients. Stroke, 38(7), 2090-2095. https://doi.org/10.1161/STROKEAHA.106.478941

Medeiros, C. A. M., de Bruin, P. F. C., Paiva, T. R., Coutinho, W. M., Ponte, R. P., \& de Bruin, V. M. S. (2011). Clinical outcome after acute ischaemic stroke: the influence of restless legs syndrome. European Journal of Neurology, 18(1), 144-149. https://doi.org/10.1111/j.1468-1331.2010.03099.x

Medeiros, C. A. M., de Bruin, V. M. S., de Castro-Silva, C., Araújo, S. M. H. A., Chaves Junior, C. M., \& de Bruin, P. F. C. (2011). Neck circumference, a bedside clinical feature related to mortality of acute ischemic stroke. Revista Da Associacao Medica Brasileira, 57(5), 559-564. https://doi.org/10.1590/S0104-42302011000500015

Michael, K. M., Allen, J. K., \& Macko, R. F. (2006). Fatigue After Stroke: Relationship to Mobility, Fitness, Ambulatory Activity, Social Support, and Falls Efficacy. Rehabilitation Nursing, 31(5), 210-217. https://doi.org/10.1002/j.2048-7940.2006.tb00137.x

Michael, K., \& Macko, R. F. (2007). Ambulatory Activity Intensity Profiles, Fitness, and Fatigue in Chronic Stroke. Topics in Stroke Rehabilitation, 14(2), 5-12. https://doi.org/10.1310/tsr1402-5

Miller, K. K., Combs, S. A., Van Puymbroeck, M., Altenburger, P. A., Kean, J., Dierks, T. A., \& Schmid, A. A. (2013). Fatigue and Pain: Relationships with Physical Performance and Patient Beliefs after Stroke. Topics in Stroke Rehabilitation, 20(4), 347-355. https://doi.org/10.1310/tsr2004-347

Morsund, Å. H., Ellekjær, H., Gramstad, A., Reiestad, M. T., Midgard, R., Sando, S. B., Jonsbu, E., \& Næss, $H$. (2019). The development of cognitive and emotional impairment after a minor stroke: $A$ longitudinal study. Acta Neurologica Scandinavica, 140(4), 281-289. https://doi.org/10.1111/ane.13143

Mutai, H., Furukawa, T., Houri, A., Suzuki, A., \& Hanihara, T. (2017). Factors associated with multidimensional aspect of post-stroke fatigue in acute stroke period. Asian Journal of Psychiatry, 26, 1-5. https://doi.org/10.1016/j.ajp.2016.12.015

Naess, H., Lunde, L., \& Brogger, J. (2012). The Triad of Pain, Fatigue and Depression in Ischemic Stroke Patients: The Bergen Stroke Study. Cerebrovascular Diseases, 33(5), 461-465. https://doi.org/10.1159/000336760

Nakase, T., Tobisawa, M., Sasaki, M., \& Suzuki, A. (2016). Outstanding Symptoms of Poststroke Depression during the Acute Phase of Stroke. PloS One , 11(10), e0163038. https://doi.org/10.1371/journal.pone.0163038

Nguyen, S., Wong, D., McKay, A., Rajaratnam, S. M. W., Spitz, G., Williams, G., Mansfield, D., \& Ponsford, J. L. (2019). Cognitive behavioural therapy for post-stroke fatigue and sleep disturbance: a pilot randomised controlled trial with blind assessment. Neuropsychological Rehabilitation, 29(5), 723738. https://doi.org/10.1080/09602011.2017.1326945 
Oliveira, G. da P., Truzzi, G., Lima, F. C. B., \& Coelho, F. M. S. (2018). A rare differential diagnosis of excessive daytime sleepiness - Artery of Percheron territory infarct. Sleep Science, 11(1), 25-27. https://doi.org/10.5935/1984-0063.20180006

Pajediene, E., Pajeda, A., Urnieziute, G., Paulekas, E., Liesiene, V., Bileviciute-Ljungar, I., Jurkeviciene, G., Rastenyte, D., \& Petrikonis, K. (2020). Subjective and objective features of sleep disorders in patients with acute ischemic or haemorrhagic stroke: It is not only sleep apnoea which is important. Medical Hypotheses, 136, 109512. https://doi.org/10.1016/j.mehy.2019.109512

Pálsdóttir, A., Stigmar, K., Norrving, B., Grahn, P., Petersson, I., Åström, M., \& Pessah-Rasmussen, H. (2020). Nature-based rehabilitation to reduce post-stroke fatigue is not effective: A randomized controlled trial. Journal of Rehabilitation Medicine. https://doi.org/10.2340/16501977-2652

Park, J. Y., Chun, M. H., Kang, S. H., Lee, J. A., Kim, B. R., \& Shin, M. J. (2009). Functional Outcome in Poststroke Patients With or Without Fatigue. American Journal of Physical Medicine \& Rehabilitation, 88(7), 554-558. https://doi.org/10.1097/PHM.0b013e3181a0dae0

Parks, N. E., Eskes, G. A., Gubitz, G. J., Reidy, Y., Christian, C., \& Phillips, S. J. (2012). Fatigue Impact Scale Demonstrates Greater Fatigue in Younger Stroke Survivors. Canadian Journal of Neurological Sciences / Journal Canadien Des Sciences Neurologiques, 39(5), 619-625. https://doi.org/10.1017/S0317167100015353

Parra, O., Sánchez-Armengol, Á., Capote, F., Bonnin, M., Arboix, A., Campos-Rodríguez, F., PérezRonchel, J., Durán-Cantolla, J., Martínez-Null, C., de la Peña, M., Jiménez, M. C., Masa, F., Casadon, I., Alonso, M. L., \& Macarrón, J. L. (2015). Efficacy of continuous positive airway pressure treatment on 5-year survival in patients with ischaemic stroke and obstructive sleep apnea: a randomized controlled trial. Journal of Sleep Research, 24(1), 47-53. https://doi.org/10.1111/jsr.12181

Patel, N., Raissi, A., Elias, S., Kamra, M., Kendzerska, T., Murray, B. J., \& Boulos, M. I. (2018). A Modified Definition for Obstructive Sleep Apnea in Home Sleep Apnea Testing after Stroke or Transient Ischemic Attack. Journal of Stroke and Cerebrovascular Diseases, 27(6), 1524-1532. https://doi.org/10.1016/j.jstrokecerebrovasdis.2017.12.052

Pihlaja, R., Uimonen, J., Mustanoja, S., Tatlisumak, T., \& Poutiainen, E. (2014). Post-stroke fatigue is associated with impaired processing speed and memory functions in first-ever stroke patients. Journal of Psychosomatic Research, 77(5), 380-384. https://doi.org/10.1016/j.jpsychores.2014.08.011

Ponchel, A., Labreuche, J., Bombois, S., Delmaire, C., Bordet, R., \& Hénon, H. (2016). Influence of Medication on Fatigue Six Months after Stroke. Stroke Research and Treatment, 2016, 1-9. https://doi.org/10.1155/2016/2410921

Ramírez-Moreno, J. M., Muñoz-Vega, P., Alberca, S. B., \& Peral-Pacheco, D. (2019). Health-Related Quality of Life and Fatigue After Transient Ischemic Attack and Minor Stroke. Journal of Stroke and Cerebrovascular Diseases, 28(2), 276-284.

https://doi.org/10.1016/j.jstrokecerebrovasdis.2018.09.046 
Redgrave, J. N., Moore, L., Oyekunle, T., Ebrahim, M., Falidas, K., Snowdon, N., Ali, A., \& Majid, A. (2018). Transcutaneous Auricular Vagus Nerve Stimulation with Concurrent Upper Limb Repetitive Task Practice for Poststroke Motor Recovery: A Pilot Study. Journal of Stroke and Cerebrovascular Diseases, 27(7), 1998-2005. https://doi.org/10.1016/j.jstrokecerebrovasdis.2018.02.056

Reeves, S. L., Brown, D. L., Chervin, R. D., Morgenstern, L. B., Smith, M. A., \& Lisabeth, L. D. (2014). Agreement between stroke patients and family members for ascertaining pre-stroke risk for sleep apnea. Sleep Medicine, 15(1), 121-124. https://doi.org/10.1016/j.sleep.2013.09.010

Riley, E. A., Owora, A., McCleary, J., \& Anderson, A. (2019). Sleepiness, Exertion Fatigue, Arousal, and Vigilant Attention in Persons With Chronic Aphasia. American Journal of Speech-Language Pathology, 28(4), 1491-1508. https://doi.org/10.1044/2019_AJSLP-18-0301

RÖDING, J., LINDSTRÖM, B., MALM, J., \& ÖHMAN, A. (2003). Frustrated and invisible--younger stroke patients' experiences of the rehabilitation process. Disability and Rehabilitation, 25(15), 867-874. https://doi.org/10.1080/0963828031000122276

Rogeau, C., Beaucamp, F., Allart, E., Daveluy, W., \& Rousseaux, M. (2014). Pilot assessment of a comfort scale in stroke patients. Journal of the Neurological Sciences, 339(1-2), 102-107. https://doi.org/10.1016/j.jns.2014.01.032

Rothwell, K., Boaden, R., Bamford, D., \& Tyrrell, P. J. (2013). Feasibility of assessing the needs of stroke patients after six months using the GM-SAT. Clinical Rehabilitation, 27(3), 264-271. https://doi.org/10.1177/0269215512457403

Ryan, A. S., Dobrovolny, C. L., Silver, K. H., Smith, G. V., \& Macko, R. F. (2000). Cardiovascular fitness after stroke: Role of muscle mass and gait deficit severity. Journal of Stroke and Cerebrovascular Diseases, 9(4), 185-191. https://doi.org/10.1053/jscd.2000.7237

Ryan, C. M., Bayley, M., Green, R., Murray, B. J., \& Bradley, T. D. (2011). Influence of Continuous Positive Airway Pressure on Outcomes of Rehabilitation in Stroke Patients With Obstructive Sleep Apnea. Stroke, 42(4), 1062-1067. https://doi.org/10.1161/STROKEAHA.110.597468

Saengsuwan, J., Ungtrakul, N., Saengsuwan, J., \& Sawanyawisuth, K. (2014). Preliminary validity and reliability of a Thai Berlin questionnaire in stroke patients. BMC Research Notes, 7(1), 348. https://doi.org/10.1186/1756-0500-7-348

Sarfo, F. S., Adusei, N., Ampofo, M., Kpeme, F. K., \& Ovbiagele, B. (2018). Pilot trial of a tele-rehab intervention to improve outcomes after stroke in Ghana: A feasibility and user satisfaction study. Journal of the Neurological Sciences, 387, 94-97. https://doi.org/10.1016/j.jns.2018.01.039

Sarfo, F. S., Jenkins, C., Mensah, N. A., Saulson, R., Sarfo-Kantanka, O., Singh, A., Nichols, M., Qanungo, S., \& Ovbiagele, B. (2017). Prevalence and Predictors of Sleep Apnea Risk among Ghanaian Stroke Survivors. Journal of Stroke and Cerebrovascular Diseases, 26(7), 1602-1608. https://doi.org/10.1016/j.jstrokecerebrovasdis.2017.02.027 
Schepers, V., Post, M., Visser-Meily, A., van de Port, I., Akhmouch, M., \& Lindeman, E. (2009). Prediction of depressive symptoms up to three years post-stroke. Journal of Rehabilitation Medicine, 41(11), 930-935. https://doi.org/10.2340/16501977-0446

Schepers, V. P., Visser-Meily, A. M., Ketelaar, M., \& Lindeman, E. (2006). Poststroke Fatigue: Course and Its Relation to Personal and Stroke-Related Factors. Archives of Physical Medicine and Rehabilitation, 87(2), 184-188. https://doi.org/10.1016/j.apmr.2005.10.005

Shiina, T., Suzuki, K., Okamura, M., Matsubara, T., \& Hirata, K. (2019). Restless legs syndrome and its variants in acute ischemic stroke. Acta Neurologica Scandinavica, 139(3), 260-268. https://doi.org/10.1111/ane.13055

Sico, J. J., Yaggi, H. K., Ofner, S., Concato, J., Austin, C., Ferguson, J., Qin, L., Tobias, L., Taylor, S., Vaz Fragoso, C. A., McLain, V., Williams, L. S., \& Bravata, D. M. (2017). Development, Validation, and Assessment of an Ischemic Stroke or Transient Ischemic Attack-Specific Prediction Tool for Obstructive Sleep Apnea. Journal of Stroke and Cerebrovascular Diseases, 26(8), 1745-1754. https://doi.org/10.1016/j.jstrokecerebrovasdis.2017.03.042

Siengsukon, C., \& Boyd, L. A. (2009). Sleep Enhances Off-line Spatial and Temporal Motor Learning After Stroke. Neurorehabilitation and Neural Repair, 23(4), 327-335. https://doi.org/10.1177/1545968308326631

Simpson, D. B., Breslin, M., Cumming, T., de Zoete, S., Gall, S. L., Schmidt, M., English, C., \& Callisaya, M. L. (2018). Go Home, Sit Less: The Impact of Home Versus Hospital Rehabilitation Environment on Activity Levels of Stroke Survivors. Archives of Physical Medicine and Rehabilitation, 99(11), 22162221.e1. https://doi.org/10.1016/j.apmr.2018.04.012

Skånér, Y., Nilsson, G. H., Sundquist, K., Hassler, E., \& Krakau, I. (2007). Self-rated health, symptoms of depression and general symptoms at 3 and 12 months after a first-ever stroke: a municipalitybased study in Sweden. BMC Family Practice, 8(1), 61. https://doi.org/10.1186/1471-2296-8-61

Smith, O. R. F., Van Den Broek, K. C., Renkens, M., \& Denollet, J. (2008). Comparison of Fatigue Levels in Patients with Stroke and Patients with End-Stage Heart Failure: Application of the Fatigue Assessment Scale. Journal of the American Geriatrics Society, 56(10), 1915-1919. https://doi.org/10.1111/j.1532-5415.2008.01925.x

Spalletta, G. (2005). Symptom Profile of DSM-IV Major and Minor Depressive Disorders in First-Ever Stroke Patients. American Journal of Geriatric Psychiatry, 13(2), 108-115. https://doi.org/10.1176/appi.ajgp.13.2.108

Sterr, A., Kuhn, M., Nissen, C., Ettine, D., Funk, S., Feige, B., Umarova, R., Urbach, H., Weiller, C., \& Riemann, D. (2018). Post-stroke insomnia in community-dwelling patients with chronic motor stroke: Physiological evidence and implications for stroke care. Scientific Reports, 8(1), 8409. https://doi.org/10.1038/s41598-018-26630-y 
Stokes, E. K., O'Connell, C., \& Murphy, B. (2011). An investigation into fatigue post-stroke and its multidimensional nature. Advances in Physiotherapy, 13(1), 2-10.

https://doi.org/10.3109/14038196.2010.534175

Suh, M., Choi-Kwon, S., \& Kim, J. S. (2014). Sleep Disturbances After Cerebral Infarction: Role of Depression and Fatigue. Journal of Stroke and Cerebrovascular Diseases, 23(7), 1949-1955. https://doi.org/10.1016/j.jstrokecerebrovasdis.2014.01.029

Tang, W. K., Liang, H. J., Chen, Y. K., Chu, W. C. W., Abrigo, J., Mok, V. C. T., Ungvari, G. S., \& Wong, K. S. (2013). Poststroke fatigue is associated with caudate infarcts. Journal of the Neurological Sciences, 324(1-2), 131-135. https://doi.org/10.1016/j.jns.2012.10.022

Tang, W. K., Chen, Y. K., Liang, H. J., Chu, W. C. W., Mok, V. C. T., Ungvari, G. S., \& Wong, K. S. (2014). Subcortical white matter infarcts predict 1-year outcome of fatigue in stroke. BMC Neurology, 14(1), 234. https://doi.org/10.1186/s12883-014-0234-8

Tang, W. K., Liu, X. X., Chen, Y. K., Abrigo, J., Chu, W. C. W., Mok, V. C. T., Ungvari, G. S., \& Wong, K. S. (2014). Cerebral Microbleeds and Fatigue in Stroke. European Neurology, 71(5-6), 213-216. https://doi.org/10.1159/000354845

Tang, W.-K., Grace Lau, C., Mok, V., Ungvari, G. S., \& Wong, K.-S. (2015). Insomnia and health-related quality of life in stroke. Topics in Stroke Rehabilitation, 22(3), 201-207. https://doi.org/10.1179/1074935714Z.0000000026

Tang, W.-K., Lau, C. G., Mok, V., Ungvari, G. S., \& Wong, K.-S. (2015). The impact of pain on healthrelated quality of life 3 months after stroke. Topics in Stroke Rehabilitation, 22(3), 194-200. https://doi.org/10.1179/1074935714Z.0000000024

Tang, W.-K., Lu, J.-Y., Liang, H., Chan, T.-T., Mok, V., Ungvari, G. S., \& Wong, K.-S. (2011). Is Insomnia Associated With Suicidality in Stroke? Archives of Physical Medicine and Rehabilitation, 92(12), 2025-2027. https://doi.org/10.1016/j.apmr.2011.06.030

Tang, W.-K., Lu, J.-Y., Mok, V., Ungvari, G. S., \& Wong, K.-S. (2011). Is Fatigue Associated With Suicidality in Stroke? Archives of Physical Medicine and Rehabilitation, 92(8), 1336-1338.

https://doi.org/10.1016/j.apmr.2011.02.018

Ten Brink, A. F., Hajos, T. R. S., van Bennekom, C., Nachtegaal, J., Meulenbelt, H. E. J., Fleuren, J. F. M., Kouwenhoven, M., Luijkx, M. M., Wijffels, M. P., \& Post, M. W. M. (2017). Predictors of physical independence at discharge after stroke rehabilitation in a Dutch population. International Journal of Rehabilitation Research, 40(1), 37-45. https://doi.org/10.1097/MRR.0000000000000198

Terroni, L. de M. N., Fráguas, R., Lucia, M. de, Tinone, G., Mattos, P., losifescu, D. V, \& Scaf, M. (2009). Importance of retardation and fatigue/interest domains for the diagnosis of major depressive episode after stroke: a four months prospective study. Revista Brasileira de Psiquiatria, 31(3), 202207. https://doi.org/10.1590/S1516-44462009000300004 
Thompson, H. S., \& Ryan, A. (2009). The impact of stroke consequences on spousal relationships from the perspective of the person with stroke. Journal of Clinical Nursing, 18(12), 1803-1811.

https://doi.org/10.1111/j.1365-2702.2008.02694.x

Tistad, M., Ytterberg, C., Tham, K., \& von Koch, L. (2012). Poor concurrence between disabilities as described by patients and established assessment tools three months after stroke: A mixed methods approach. Journal of the Neurological Sciences, 313(1-2), 160-166. https://doi.org/10.1016/j.jns.2011.08.038

Türkbey, T., Kutlay, S., \& Gök, H. (2017). Clinical feasibility of Xbox KinectTM training for stroke rehabilitation: A single-blind randomized controlled pilot study. Journal of Rehabilitation Medicine, 49(1), 22-29. https://doi.org/10.2340/16501977-2183

van de Port, I. G. L., van den Bos, G. A. M., Voorendt, M., Kwakkel, G., \& Lindeman, E. (2007). Identification of risk factors related to perceived unmet demands in patients with chronic stroke. Disability and Rehabilitation, 29(24), 1841-1846. https://doi.org/10.1080/09638280601129157

van de Port, I. G. L., Kwakkel, G., Schepers, V. P. M., Heinemans, C. T. I., \& Lindeman, E. (2007). Is Fatigue an Independent Factor Associated with Activities of Daily Living, Instrumental Activities of Daily Living and Health-Related Quality of Life in Chronic Stroke? Cerebrovascular Diseases, 23(1), 40-45. https://doi.org/10.1159/000095757

van de Port, I., Kwakkel, G., \& Lindeman, E. (2008). Community ambulation in patients with chronic stroke: how is it related to gait speed? Journal of Rehabilitation Medicine, 40(1), 23-27. https://doi.org/10.2340/16501977-0114

van de Port, I. G. L., Kwakkel, G., Bruin, M., \& Lindeman, E. (2007). Determinants of depression in chronic stroke: A prospective cohort study. Disability and Rehabilitation, 29(5), 353-358. https://doi.org/10.1080/09638280600787047

van de Port, I. G. L., Kwakkel, G., van Wijk, I., \& Lindeman, E. (2006). Susceptibility to Deterioration of Mobility Long-Term After Stroke. Stroke, 37(1), 167-171. https://doi.org/10.1161/01.STR.0000195180.69904.f2

van der Zee, C. H., Visser-Meily, J. M. A., Lindeman, E., Jaap Kappelle, L., \& Post, M. W. M. (2013). Participation in the Chronic Phase of Stroke. Topics in Stroke Rehabilitation, 20(1), 52-61. https://doi.org/10.1310/tsr2001-52

van Rijsbergen, M. W. A., Mark, R. E., Kop, W. J., de Kort, P. L. M., \& Sitskoorn, M. M. (2019). Psychological factors and subjective cognitive complaints after stroke: Beyond depression and anxiety. Neuropsychological Rehabilitation, 29(10), 1671-1684. https://doi.org/10.1080/09602011.2018.1441720

van Rijsbergen, M. W. A., Mark, R. E., Kop, W. J., de Kort, P. L. M., \& Sitskoorn, M. M. (2020). Course and Predictors of Subjective Cognitive Complaints During the First 12 Months after Stroke. Journal of Stroke and Cerebrovascular Diseases, 29(3), 104588. https://doi.org/10.1016/j.jstrokecerebrovasdis.2019.104588 
van Vugt, F. T., Kafczyk, T., Kuhn, W., Rollnik, J., Tillmann, B., \& Altenmüller, E. (2016). The role of auditory feedback in music-supported stroke rehabilitation: A single-blinded randomised controlled intervention. Restorative Neurology and Neuroscience, 34(2), 297-311. https://doi.org/10.3233/RNN-150588

Van Vugt, F. T., Ritter, J., Rollnik, J. D., \& Altenmuller, E. (2014). Music-supported motor training after stroke reveals no superiority of synchronization in group therapy. Frontiers in Human Neuroscience, 8, 315. https://doi.org/10.3389/fnhum.2014.00315

van Wijk, I., Algra, A., van de Port, I. G., Bevaart, B., \& Lindeman, E. (2006). Change in Mobility Activity in the Second Year After Stroke in a Rehabilitation Population: Who is at Risk for Decline? Archives of Physical Medicine and Rehabilitation, 87(1), 45-50. https://doi.org/10.1016/j.apmr.2005.08.118

Van Zandvoort, M. J. E., Kappelle, L. J., Algra, A., \& De Haan, E. H. F. (1998). Decreased capacity for mental effort after single supratentorial lacunar infarct may affect performance in everyday life. Journal of Neurology, Neurosurgery \& Psychiatry, 65(5), 697-702. https://doi.org/10.1136/jnnp.65.5.697

Vock, J., Achermann, P., Bischof, M., Milanova, M., Muller, C., Nirkko, A., Roth, C., \& Bassetti, C. L. (2002). Evolution of sleep and sleep EEG after hemispheric stroke. Journal of Sleep Research, 11(4), 331-338. https://doi.org/10.1046/j.1365-2869.2002.00316.x

Vuletić, V., Ležaić, Ž., \& Morović, S. (2011). Post-stroke fatigue. Acta Clinica Croatica, 50(3), 344. https://www.scopus.com/inward/record.uri?eid=2-s2.084865106803\&partnerlD=40\&md5=7f2fdde8b688d8c3311f7db8777745e2

Walsh, M. E., Galvin, R., Loughnane, C., Macey, C., \& Horgan, N. F. (2015). Community re-integration and long-term need in the first five years after stroke: results from a national survey. Disability and Rehabilitation, 37(20), 1834-1838. https://doi.org/10.3109/09638288.2014.981302

Wang, S.-S., Wang, J.-J., Wang, P.-X., \& Chen, R. (2014). Determinants of Fatigue after First-Ever Ischemic Stroke during Acute Phase. PLoS ONE, 9(10), e110037. https://doi.org/10.1371/journal.pone.0110037

Wendel, K., Risberg, J., Pessah-Rasmussen, H., Ståhl, A., \& Iwarsson, S. (2008). Long-term cognitive functional limitations post stroke: objective assessment compared with self-evaluations and spouse reports. International Journal of Rehabilitation Research. Internationale Zeitschrift Fur Rehabilitationsforschung. Revue Internationale De Recherches De Readaptation, 31(3), 231-239. https://doi.org/10.1097/MRR.0b013e3283021912

West, A., Simonsen, S. A., Zielinski, A., Cyril, N., Schønsted, M., Jennum, P., Sander, B., \& Iversen, H. K. (2019). An exploratory investigation of the effect of naturalistic light on depression, anxiety, and cognitive outcomes in stroke patients during admission for rehabilitation: A randomized controlled trial. NeuroRehabilitation, 44(3), 341-351. https://doi.org/10.3233/NRE-182565 
Westergren, A. (2008). Nutrition and its Relation to Mealtime Preparation, Eating, Fatigue and Mood Among Stroke Survivors After Discharge from Hospital - A Pilot Study. The Open Nursing Journal, 2(1), 15-20. https://doi.org/10.2174/1874434600802010015

White, J. H., Gray, K. R., Magin, P., Attia, J., Sturm, J., Carter, G., \& Pollack, M. (2012). Exploring the experience of post-stroke fatigue in community dwelling stroke survivors: a prospective qualitative study. Disability and Rehabilitation, 34(16), 1376-1384. https://doi.org/10.3109/09638288.2011.645111

Widar, M., Ek, A.-C., \& Ahlström, G. (2004). Coping with long-term pain after a stroke. Journal of Pain and Symptom Management, 27(3), 215-225. https://doi.org/10.1016/j.jpainsymman.2003.07.006

Williams, L. S., Weinberger, M., Harris, L. E., Clark, D. O., \& Biller, J. (1999). Development of a StrokeSpecific Quality of Life Scale. Stroke, 30(7), 1362-1369. https://doi.org/10.1161/01.STR.30.7.1362

Winkens, I., Van Heugten, C. M., Wade, D. T., Habets, E. J., \& Fasotti, L. (2009). Efficacy of Time Pressure Management in Stroke Patients With Slowed Information Processing: A Randomized Controlled Trial. Archives of Physical Medicine and Rehabilitation, 90(10), 1672-1679. https://doi.org/10.1016/j.apmr.2009.04.016

Winkens, I., Van Heugten, C. M., Fasotti, L., \& Wade, D. T. (2009). Reliability and validity of two new instruments for measuring aspects of mental slowness in the daily lives of stroke patients. Neuropsychological Rehabilitation, 19(1), 64-85. https://doi.org/10.1080/09602010801913650

Worthington, E., Hawkins, L., Lincoln, N., \& Drummond, A. (2017). The day-to-day experiences of people with fatigue after stroke: Results from the Nottingham Fatigue After Stroke study. International Journal of Therapy and Rehabilitation, 24(10), 449-455. https://doi.org/10.12968/ijtr.2017.24.10.449

Yang, S., \& Kong, K. (2013). Level and predictors of participation in patients with stroke undergoing inpatient rehabilitation. Singapore Medical Journal, 54(10), 564-568. https://doi.org/10.11622/smedj.2013201

Yayla, V., Erdoğan, H. A., Aydin, F., Vural, M., Çabalar, M., Ersoy, S., \& Çakmak Bozan, B. (2016). Poststroke fatigue and its effect on functional status and quality of life in patient with ischemic stroke . Journal of Neurological Sciences, 33(3), 424-432. https://www.scopus.com/inward/record.uri?eid=2-s2.085018817979\&partnerID=40\&md5=adcf723ac5b2964470e1a8c42cb1253b

Zedlitz, A. M. E. E., Visser-Meily, A. J. M. A., Schepers, V. P., Geurts, A. C. H., \& Fasotti, L. (2011). Patients with Severe Poststroke Fatigue Show a Psychosocial Profile Comparable to Patients with Other Chronic Disease: Implications for Diagnosis and Treatment. ISRN Neurology, 2011, 1-8. https://doi.org/10.5402/2011/627081

Zhang, L., Zeng, T., Gui, Y., Sun, Y., Xie, F., Zhang, D., \& Hu, X. (2019). Application of Neck Circumference in Four-Variable Screening Tool for Early Prediction of Obstructive Sleep Apnea in Acute Ischemic 
Stroke Patients. Journal of Stroke and Cerebrovascular Diseases, 28(9), 2517-2524.

https://doi.org/10.1016/j.jstrokecerebrovasdis.2019.06.011 